\title{
A Study on Electric Vehicles Participating in the Load Regulation of Urban Complexes
}

\author{
Qiwei Xu ${ }^{1}$, Jianshu Huang ${ }^{1}{ }^{1}$, Yue Han ${ }^{2}$, Yun Yang ${ }^{1}$ and Lingyan Luo ${ }^{1, *}$ \\ 1 State Key Laboratory of Power Transmission Equipment \& System Security and New Technology, \\ Chongqing University, Chongqing 400044, China; huangjs@cqu.edu.cn (Q.X.); 20132160@cqu.edu.cn (J.H.); \\ 201734131008@cqu.edu.cn (Y.Y.) \\ 2 Northeast Branch of State Grid Corporation of China, Shenyang 110180, China; yuehanying@163.com \\ * Correspondence: luoly@cqu.edu.cn
}

Received: 6 April 2020; Accepted: 4 June 2020; Published: 8 June 2020

\begin{abstract}
Urban complex (UC) is the main place of citizens' life and work. The construction of an UC often needs to expand the capacity of the power equipment. This paper proposes to use electric vehicles (EVs) in an UC to reduce the power load of the UC during peak periods, so that lower capacity power equipment can be used to reduce the construction costs of the UC and the transformation of electrical facilities. In order to find the relationship between parking and power load in the UC, the UC is decomposed into different functional areas for research. Then, we build a parking information database for clustering and calculation. Divide the load peak into adjustment intervals of equal duration. The EVs parked in the UC for each regulation interval (RI) are grouped according to parking characteristics. Establish an objective function with the minimum load variance during peak hours. The discharge capacity of each group in each RI is obtained and distributed to each EV to realize peak load reduction of UC. Finally, the results of case analysis show that the strategy can reduce the peak load effectively thus save the cost of UC construction.
\end{abstract}

Keywords: electric vehicle; V2G; urban complex; peak shaving; smart grid

\section{Introduction}

The consumption of fossil fuels has brought about serious ecological issues such as global warming and air pollution. The promotion of electric vehicles (EVs) can effectively solve these problems. Therefore, many countries have promulgated various policies to support the development of EVs. It can be predicted that the number of EVs will increase rapidly in the future. The large-scale popularization of EVs will require huge demand for electricity. As electricity consumers, uncontrolled charging of many EVs may cause unsafe operations in the power grid, but EVs can also be used as mobile energy storage for load regulation. Hence, proper control of EVs' charging and discharging will have an important impact on the construction and operation of the power grid. As the busiest place for people and cars gathering in the city, the urban complex (UC) has high electricity demand. The construction of UCs will cause the reconstruction and expansion of the surrounding distribution power grid. It will cost lots of money for reconstruction and expansion of the power grid. To solve this problem, we will mainly study EVs with the function of participating in the load regulation of UC.

There are many studies on charging load mode of EVs at present. In order to establish the charging load model of EV cluster in charging stations and residential areas, a queuing theory modeling method was employed in [1]. Based on the National Household Travel Survey (NHTS) database of the United States Department of Transportation in 2009, the statistical rules of EV trips, ending time and driving distance are studied and analyzed. On this basis, the probable charging model of EVs was completed in [2]. Considering the price and tax rate, fuel price, policy support and charging safety of 
EVs, a forecasting method based on an agent model was proposed and used to predict the development scale of EVs in Iceland from 2012 to 2030 in [3]. A statistical analysis of the 24-hour travel of EVs was carried out, and the load curve of charging at home was calculated in [4]. An Autoregressive Integrated Moving Average model (ARIMA) method for demand forecasts of conventional electrical load and charging demand of EVs' parking lots was presented in [5], and the parameters of the ARIMA model should be tuned so that the mean square error of the forecaster could be minimized. Researchers in [6] pointed out that in the United Kingdom, EVs with 10\% permeability would lead to a $17.9 \%$ increase in peak power demand per day, and a $35.8 \%$ increase if permeability reaches $20 \%$.

The strategies of peak-shaving and valley-filling are one of the research focuses. A time-sharing charging control strategy for EVs based on the predicted load curve is presented in [7]. By increasing the tariff during the peak load period and reducing the tariff during low load period, users can choose to charge during low load period to realize peak shift [8]. Researchers in [9-11] established the simulation model of EV participating in load frequency adjustment and study its mechanism and control effect. They demonstrated the feasibility of EV participating in grid frequency regulation. When the grid frequency is high, controlling a large number of EVs charging promotes the frequency of the grid to decline; and when the grid frequency is low, controlling a large number of EVs discharge promotes the frequency of power grid to rise. Scholars simulate and calculate the potential benefits of $250 \mathrm{EVs}$ participating in grid regulation in New England. The calculation results show that when EV only provides downward FM service (the EV only charges), each EV can bring about an annual revenue of \$700-900. When the EV provides both upward and downward FM service (EVs both charge and discharge), each EV can annually generate revenue of $\$ 1250$ to $\$ 1400$ for its users [12].

The authors in [13] proposed a stochastic unit commitment for isolated power systems in which the risk of high operating costs is limited using the conditional value-at-risk risk measure. A unit commitment formulation that accounts for the requirements of spinning reserves was presented in [14]. A procedure to determine the optimal design of an isolated system with a high penetration of renewable energy sources was proposed in [15]. Several electric vehicle charging algorithms were proposed explicitly considering their negative impacts on the transmission and distribution grids in [16]. An agent-based coordinated dispatch strategy for electric vehicles and renewable units at distribution level was presented in [17]. A reserve contract optimization model designed for electric vehicles with vehicle-to-grid capability was proposed in [18]. The authors in [19] investigated the optimal planning of the Nordic transmission system in 2050 for a $100 \%$ electric vehicle penetration.

Researchers in [20] found that V2G strategy effectively reduced contamination emissions and cut down the investment of variable load plants. Researchers in [21] also considered that the participation of V2G into power systems could reduce peak power generation costs. The authors in [22] believed that V2G application of heavy-duty electric vehicles was not only possible but also necessary for more profits while electric buses without V2G revenue would not be cost-effective compared with traditional diesel buses. The results in [23] showed that electric trucks could generate an additional enormous income for owners if they provided V2G regulation service. The authors in [24] proposed a two-stage approximate dynamic programming framework for the optimal charging strategy in a commercial building parking lot and simulates a number of scenarios where the vehicle arrival behavior is modeled as a Poisson process.

The coordination of EVs and distributed energy sources is another research focus. When there are enough intelligent generators, power electronic devices and interactive chargers in the power grid, EVs can be used as energy storage devices and standby power supply in case of accidental power outages [25-28]. EVs can help integrate intermittent renewable energy such as wind and solar energy into the grid more efficiently. V2G system can provide more help for grid operators, including reactive power support, active power regulation, and load balancing through peak shaving and valley filling, current harmonic filtering. These systems can provide auxiliary services such as frequency control and rotating reserve, which can significantly improve the efficiency, stability and reliability of power grid [29-32]. According to the Demand Side Management (DSM) method, the charging and 
discharging status of EVs will change with the load, which can not only improve the reliability of power grid operation, but also reduce the impact on power grid if a large number of EVs are connected to the power grid [33]. A strategy to optimize the control of EV group, not only considering the cost of EV users, but also considering the benefits of EVs accessing the grid to participate in auxiliary peak shaving, frequency modulation and standby [34,35]. EV clusters and a double-level optimal strategy are used according to different priorities in [36], and a real-time optimal strategy from EV clusters to individuals is completed.

We can find that most of studies have considered that EVs should charge or discharge at the charging station. In fact, users prefer to charge near home because the charging stations are always located in remote places. The smart city is a new urban construction concept. This means the integration of urban function and services to optimize efficiency of urban management and services. It will improve the quality of citizens' life. The UC is generally located in busy areas with business, office, residential functions and so on. This aligns with the smart cities concept. Many people live near the UC. Obviously, it is a better choice for users to charge and discharge in the UC. It is convenient for people if we build the garage of an UC as a charging and discharging power station. This design can not only meet the charging needs of users, but also let EVs participate in the load regulation of the UC. Therefore, EVs participating in the load regulation of UC can facilitate the safe and stable operation of the power grid and efficient utilization of power resources in a smart city. This is conducive to establishing the power supply systems of smart cities. However, there are few studies about EVs participating in load regulation of an UC. The vehicle behavior of UCs is very complex. There are many cars of malls, consumers, white-collar workers and residents in an UC, so the relationship between the load characteristics and parking characteristics of different functional areas is obtained by studying the different function areas of an UC in our research. Then, the EVs are clustered into a controllable group and an uncontrollable group. Each group will be regarded as a whole to participate in the load regulation of the UC. In order to make more EVs with different parking times participate in the load regulation, we divide the peak load period into many small time periods defined as the regulation interval (RI). In this way, if the parking time of some vehicles can cover a certain RI, the vehicles can participate in the load regulation of this RI. We set the objective function which minimize the mean square deviation of load and get the total discharge power of each group in each RI and allocate it to each vehicle. Last, the case study proved that the EVs can reduce the peak load of UC effectively. In summary, the main contributions of our research are:

(1) The random charging load model of EVs is established according to the daily travel habits of residents. The influence of the EVs' number and charging power on the charging load is analyzed. It is confirmed that large-scale EV use with random charging will produce a serious charging load, which will influence the safe operation of the power grid.

(2) The construction of UCs is becoming more and more popular among real estate developers. There are few studies about EVs participating in load regulation of UCs. The research carried out in this paper can reduce the peak load of UCs and improve the security of local power grid operation.

(3) It is proposed to divide the UC into different functional areas. Then, we get the relationships between load ratio and parking ratio of these different functional areas. The vehicles parked in the UC are divided into three groups according to the functional areas of the UC. The problem is simplified by this way.

(4) We propose a load shaving strategy involving three types according to their controllability, and the objective function was established to minimize load variance during the peak period of the UC. A case study was done to verify the strategy. The result proves that the strategy proposed in the paper can effectively reduce the peak load through appropriate parameter matching, which is safe to the operation of the power grid. 
The rest of the paper is organized as follows: Section 2 describes the problem faced by EV charging. The calculation model of random charging load of EVs is established according to the user's habit. Then, the relationship between load and parking of the UC is studied. The relationship between load ratio and parking ratio can be obtained by decomposing the UC into different functional areas. In Section 3, the EV discharging strategies in UCs are illustrated and thoroughly described. In Section 4, the effectiveness of the strategy is verified by case study, and the influence of permeability and length of regulation interval on peak shaving is analyzed. Finally, the conclusions are presented in Section 5.

\section{Model Description}

With the increase of EVs, the concentrated charging of EVs may cause power shortages in local areas. The charge power of EVs during peak load periods will increase the burden of the distribution power network. Since the existing local distribution networks and facilities did not consider the charge demand of EVs during the construction period, they need to invest a lot of money to expand and transform the local distribution power grid for EV charging.

This section will study the influence of stochastic charge on power grid, load characteristics of the UC, the parking patterns in the UC and model the stochastic charge load of EVs. Based on this, our research further proposes a parking garage which can be used in an UC. This parking garage will be built as a charge center with the function of both parking and charge/discharge for EVs. Through the cooperation of flexible charge/discharge strategies, it can solve the problems of grid planning lag in the construction of UCs and the dangers of power grid operation which caused by the stochastic charge of EVs. In this paper, we will propose a discharge strategy for the peak load period.

\subsection{Load Model of Stochastic Charging}

With the expanded development of EVs, the number of EVs will reach a new scale. Their charging demands will increase significantly. The charge load generation by EVs will represent and ever increasing proportion of the power grid electricity consumption if the number of EVs is increasing. In addition, the charge behavior of EVs users is clustered. The peak load of the power grid will increase dramatically. It is necessary to increase the capacity of the power network to satisfy the demand of EV charging in the future. Therefore, for construction and operation of the power grid, it is particularly important to establish a model of the EVs' charging load.

The factors affecting the charging load can be summarized as battery capacity, charge power and users' behavior. The power battery capacity determines the users' charging frequency. The larger battery capacity means the lower the charging frequency. The charge power is related to the charge time. The greater charge power means the shorter charge time. At the same time, the charge power will influence the peak charge load. Compared with the objective factors mentioned above, users' behavior is the key factor affecting the charging load. The user behaviors have an impact on charging load mainly includes two aspects: the start charge time and State Of Charge (SOC). Concentration of the user's initial charging time will cause the greater the charging load. SOC reflects the user's current battery capacity consumption. If the battery capacity is small, the users generally charge every day. With the increase of the battery capacity of EV, the users' charge frequency will decrease. Our research will consider these factors and establish a power demand model of EV in one day.

According to the National Household Travel Survey 2001 of American, the daily routine mileage $s$ obeys the log-normal distribution [4]:

$$
f(s)=\frac{1}{\sqrt{2 \pi} s \delta_{D}} \exp \left[-\frac{\left(\ln s-\mu_{D}\right)^{2}}{2 \delta_{D}^{2}}\right]
$$

where, $\mu_{D}$ is the expectation of probability density function, $\delta_{D}$ is the standard deviation. 
Assume the SOC is full at the first travel in a day. The remain $S O C_{\text {end }}$ after the last travel is:

$$
S O C_{\text {end }}=1-k \cdot s
$$

where, $k$ is the SOC consumption per kilometer.

The peak time of off-duty travel of private EVs is typically 17:00-19:00 [4]. Assuming that the starting charge time is the last return time of the trip, combined with the survey results of the United States Department of Transportation on American household vehicles, the final return time of the vehicle is a normal distribution. In Equation (3), $t$ is the final return time of the vehicle, and its probability density function is as follows:

$$
f_{s}(t)= \begin{cases}\frac{1}{\delta_{s} \sqrt{2 \pi}} \exp \left[-\frac{\left(t-\mu_{s}\right)^{2}}{2 \delta_{s}^{2}}\right], & \left(\mu_{s}-12\right)<t<24 \\ \frac{1}{\delta_{s} \sqrt{2 \pi}} \exp \left[-\frac{\left(t+24-\mu_{s}\right)^{2}}{2 \delta_{s}^{2}}\right], & 0<t \leq\left(\mu_{s}-12\right)\end{cases}
$$

where $\mu_{s}$ is the expectation of probability density function, $\delta_{s}$ is the standard deviation.

The charge power of EVs is related to the characteristics of batteries. The classical three-stage charge mode is usually adopted in the charge process of lithium batteries: pre-charge stage, constant current charge stage and constant voltage charge stage. In the pre-charge stage, lithium batteries are activated to a certain state by a small current, which is usually about $10 \%$ of the constant current stage. Constant current charge stage is the main stage of charging. When the battery voltage is higher than $2 \mathrm{~V}$, the activity of the lithium-ion battery is fully activated and the internal resistance is smaller. It can accept a high current charge. Generally, this period is used to charge the battery capacity to about $80 \%$. When the voltage of the lithium battery reaches the predetermined value, the third stage of constant voltage charge is carried out. The current gradually decreases until it drops to 0 . The period of first stage and third stage are short, so the charge power can be regarded as a constant.

The charge time $t_{c}$ can be calculated according to $S O C_{e n d}$ and charge power.

$$
t_{c}=\frac{\left(1-S O C_{e n d}\right) \cdot W}{P_{c} \eta}
$$

where $P_{c}$ is the charge power; $\eta$ is the charge efficiency, chosen as 0.90 [37], $W$ is the battery capacity of the EVs. Table 1 shows the top 10 most popular EV types in 2019 in China [38]. The battery capacity of the top 10 most popular EVs in China is generally above $40 \mathrm{kWh}$, except for some mini-cars. According to the data in Table 1, the battery capacity is more than $40 \mathrm{kWh}$ after weighting the market share. With the development of electric vehicle technology, the battery capacity will be larger and larger in the future. In order to simplify the calculation process, the average capacity of power batteries is chosen as $W=40 \mathrm{kWh}$ in our research.

Table 1. Battery capacity and market share of the top10 most popular EV types in 2019 of China.

\begin{tabular}{ccc}
\hline Type & Battery Capacity (kWh) & Market Share \\
\hline BAIC EU & 53.6 & $13.3 \%$ \\
BYD Yuan EV & 40 & $7.4 \%$ \\
Baojun EV & 24 & $7.2 \%$ \\
Chery eQ & 23.6 & $4.7 \%$ \\
BYD Tang DM & 82.8 & $4.1 \%$ \\
BYD E5 & 60.48 & $3.9 \%$ \\
GAC Aion S & 49.4 & $3.9 \%$ \\
Roewe Ei5 & 52.5 & $3.7 \%$ \\
GWM R1 & 28.5 & $3.4 \%$ \\
Emgrand EV & 52 & $3.4 \%$ \\
\hline
\end{tabular}


According to the travel characteristics, the Monte Carlo method is used to simulate the charging load of EVs. Firstly, we assume the total number of EV is $N$. For the $n$-th EV, the daily routine mileage of vehicles $s^{n}$ and the final return time of the vehicle $t^{n}$ is randomly generated by Equations (1) and (3). Then, the charge time $t_{c}^{n}$ can be calculated by Equation (4). The charging load $P_{c}^{n}$ will last from $t^{n}$ to $t^{n}+t_{c}^{n}$ for the $n$-th EV. By adding up the charging load of each vehicle in each period $T$ we get the total charging load $P(T)$. Algorithm 1 in Table 2 is the calculation process of stochastic charging load of EVs.

Table 2. Calculation process of stochastic charging load of EVs.

\begin{tabular}{ll}
\hline Algorithm 1 & Calculation process of stochastic charging load of EVs. \\
\hline Input & probability density function of daily routine mileage and final return time \\
output & Random charging load $P(t)$ of EVs. \\
Step1 & Generate $s^{n}$ and $t^{n}$ by the Monte Carlo method \\
Step2 & Calculate the charge time $t_{c}^{n}$ \\
Step3 & When $n \leq N$ \\
& Add the $P_{c}^{n}$ to the $P(T)$ from $t^{n}$ to $t^{n}+t_{c}^{n}$ \\
Step4 & Output the random charging load of EVs \\
\hline
\end{tabular}

According to the calculation process, the stochastic charge load of EVs is established. We take a residential area with 1000 households as an example to calculate the stochastic charge load. Supposing there are 1000 parking spaces, of which 250 parking spaces can provide charging services. We set the charge power as $\mathrm{P}=10 \mathrm{~kW}$, and explore the influence of EV number on charge load. As can be observed from the Figure 1, the peak charge load concentrate between 19:00 and 22:00, and with the increase of EV number, the charge load will increase rapidly. When $250 \mathrm{EVs}$ are charged, the peak charge load exceeds $1000 \mathrm{~kW}$. This is a large valve for 1000 residential households.

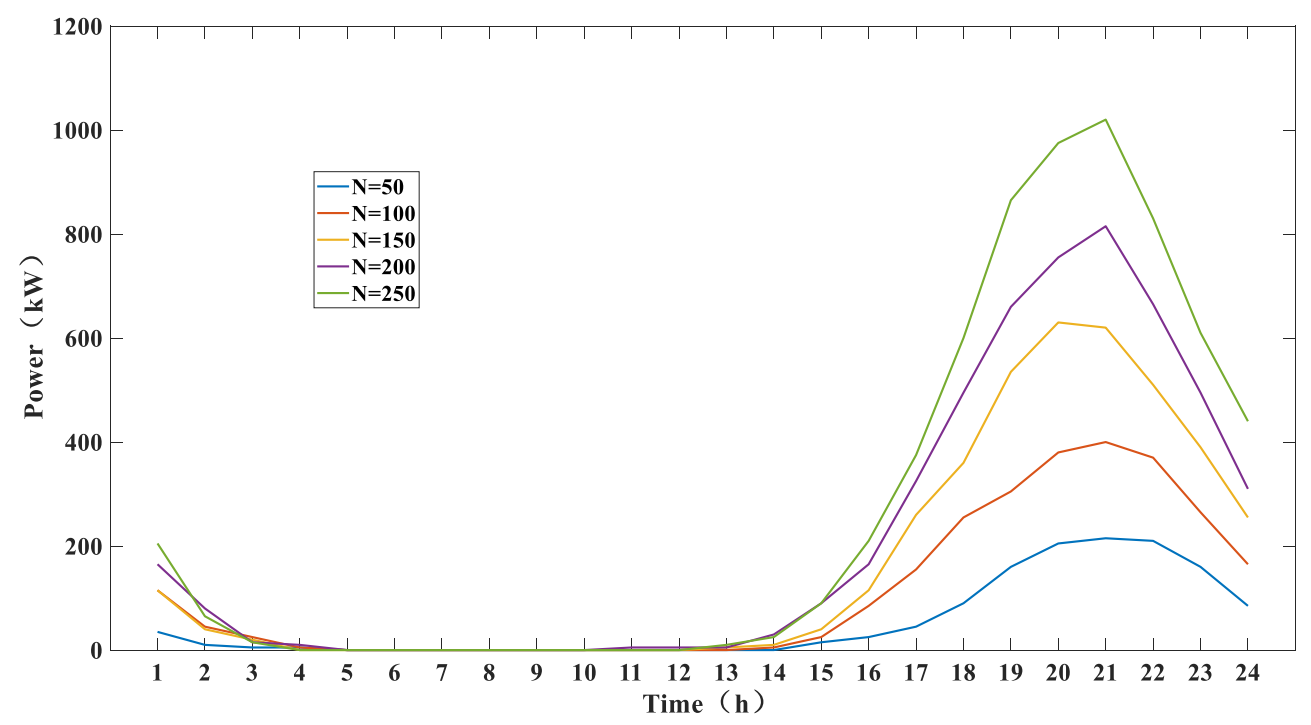

Figure 1. Uncontrolled charge load with different number of EVs when the charge power is $10 \mathrm{~kW}$.

Then, we set the number of $\mathrm{EV}$ is $\mathrm{N}=100$, and find the influence of charge power on charge load. As can be observed from Figure 2 the peak charge load will decrease with the decrease of charge power. It can reduce the charge load impact on power grid effectively. At the same time, the charge time will last long if the charge power decrease. So, if the charge power is too low, the charge period will be too long to satisfy the usage for next time. With the development of battery technology, the battery capacity will be larger and larger. The requirement of charge power will also be greater and greater. There is no point by reducing charge power simply. 


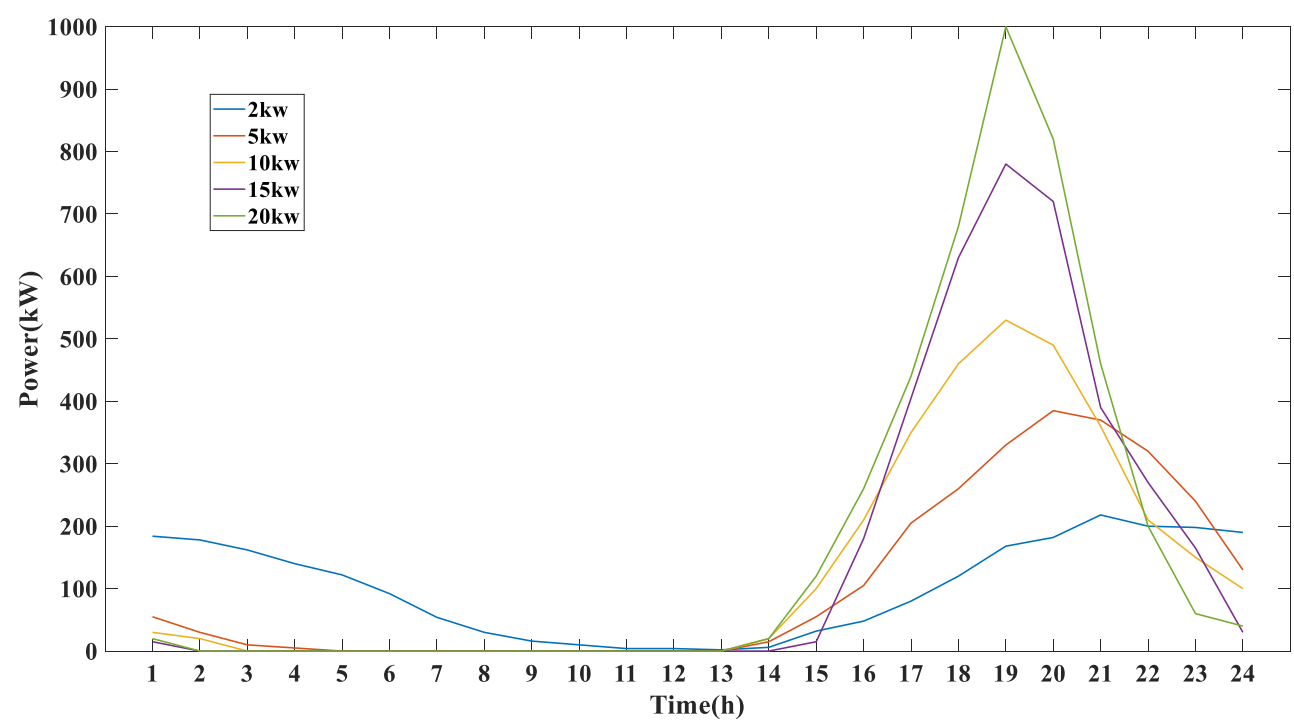

Figure 2. Uncontrolled charge load with different charge powers when the number of EVs is 100.

\subsection{Characteristic of UC Load}

As shown in Figure 3, an UC is a group of buildings with at least three of a series of functions such as shopping, entertainment, office space, accommodation, residential living and so on. Its area can reach more than hundreds of thousands of square meters or even millions of square meters. It is a multi-functional, efficient and convenient synthetic assembly, which is formed to realize the complete operation system of work and life in smart city. It can provide people with a colorful life. More and more people like to live in or near the UC. Real estate companies will also build more UCs to meet people's needs. However, in order to recoup funds as soon as possible, real estate companies need to take as little time as possible to construct an UC. There is a large demand for electricity, as a result, the original power planning of the region may not meet the needs of the UC.

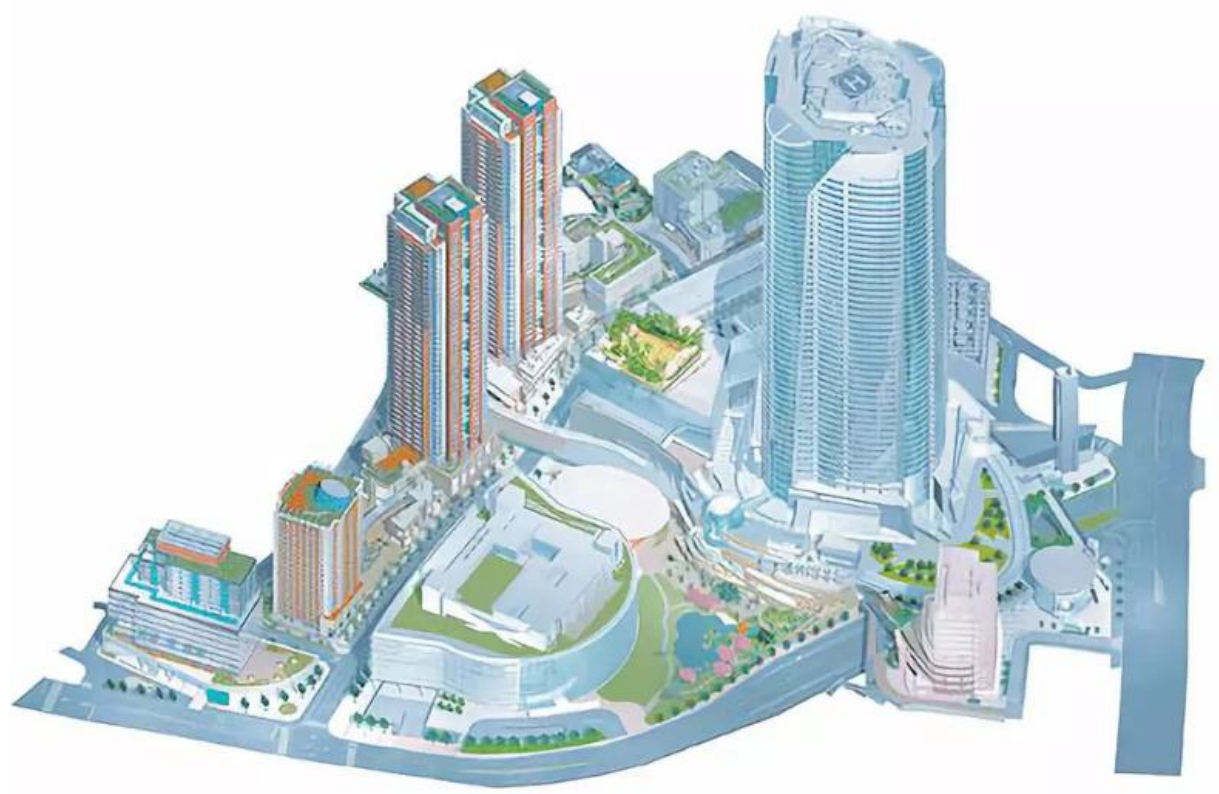

Figure 3. A typical urban complex with a huge underground parking lot. 
There are differences between different functional areas of UC in work and rest time. Therefore, the load characteristics of UC are closely related to its functions. Our research divides UC into three types of individual buildings based on the function and running time of UC: commercial type, office type and residential type. Then, the real data of different types is analyzed to get the load and parking characteristics of the different types.

Because the power load of different UC is different in different days, our research uses the load ratio to analyze the load characters at different times of the day, and randomly selects three different types of single buildings on the working day for analysis.

The load ratio $\alpha^{T}$ can be calculated by:

$$
\alpha^{T}=\frac{P_{c o n}^{T}}{P^{\max }}
$$

Figure 4 shows the load ratio curves at different times for the residential type of building. In the residential type, the load increases significantly from 8:00 a.m., with the peak occurring between 19:00 and 23:00 a.m. This is closely related to residents' living habits. Residents start a new day after waking up at about 8:00 am. Most people will leave home to work during the daytime, but some unemployed residents stay at home for their own business during the daytime on the power load remains at a low level before the other residents come back. Residents will return to the home after work at about 18:00. Then, the demand for electricity will increase. There will then be a peak of electricity consumption until the residents rest at night.

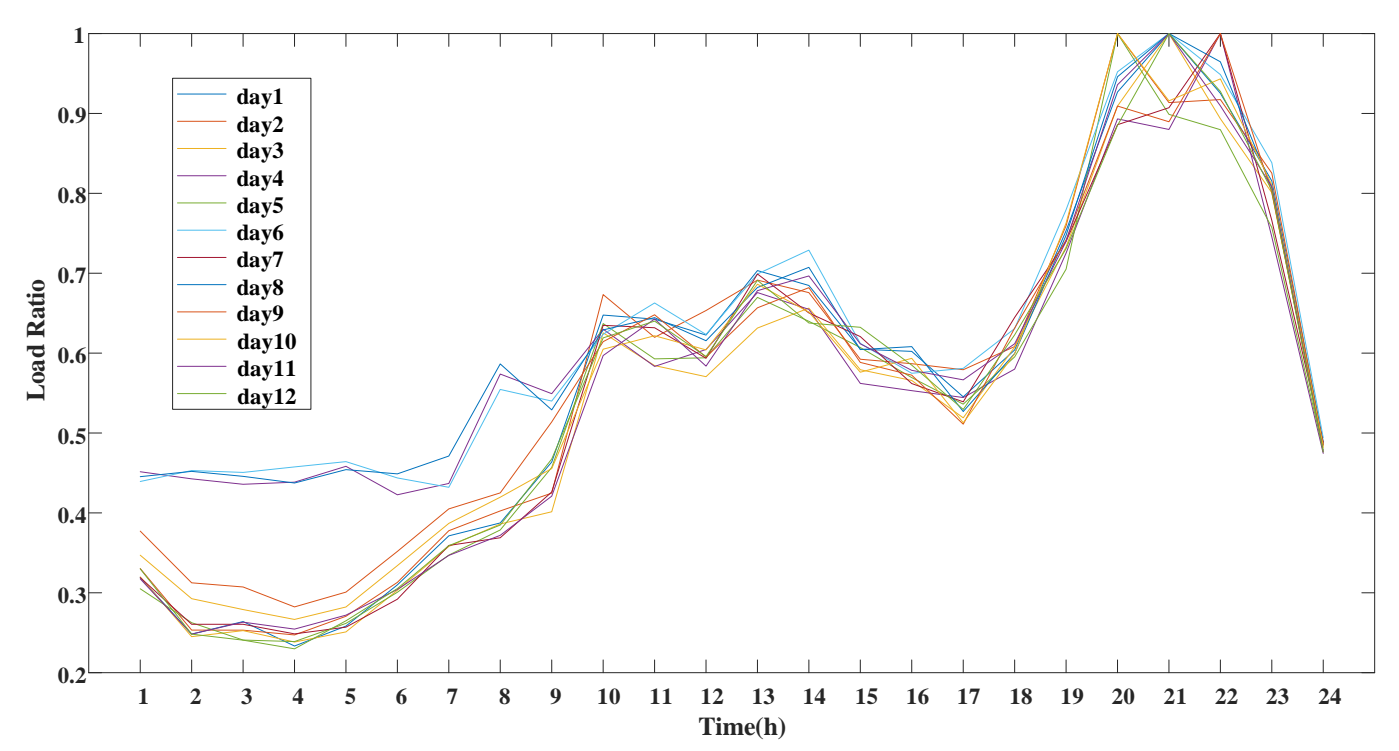

Figure 4. Load ratio curves of residential type buildings at different days.

Figure 5 shows the load ratio curve of office type buildings at different times. It is obvious that the peak load period of office type is mainly concentrated between 9:00 a.m. and 18:00 p.m. The rest of the time load the load is relatively low. The peak load period basically coincides with companies' working hours. The load ratio is relatively stable in peak and valley sections, respectively. The employees' demand for electricity is mainly concentrated on lighting, air conditioning and the consumption of office equipment such as computers during working hours. The demand for electricity is stable. During non-working hours, there is almost nobody in the office, and only a small amount of power is needed, such as emergency channel lighting. 


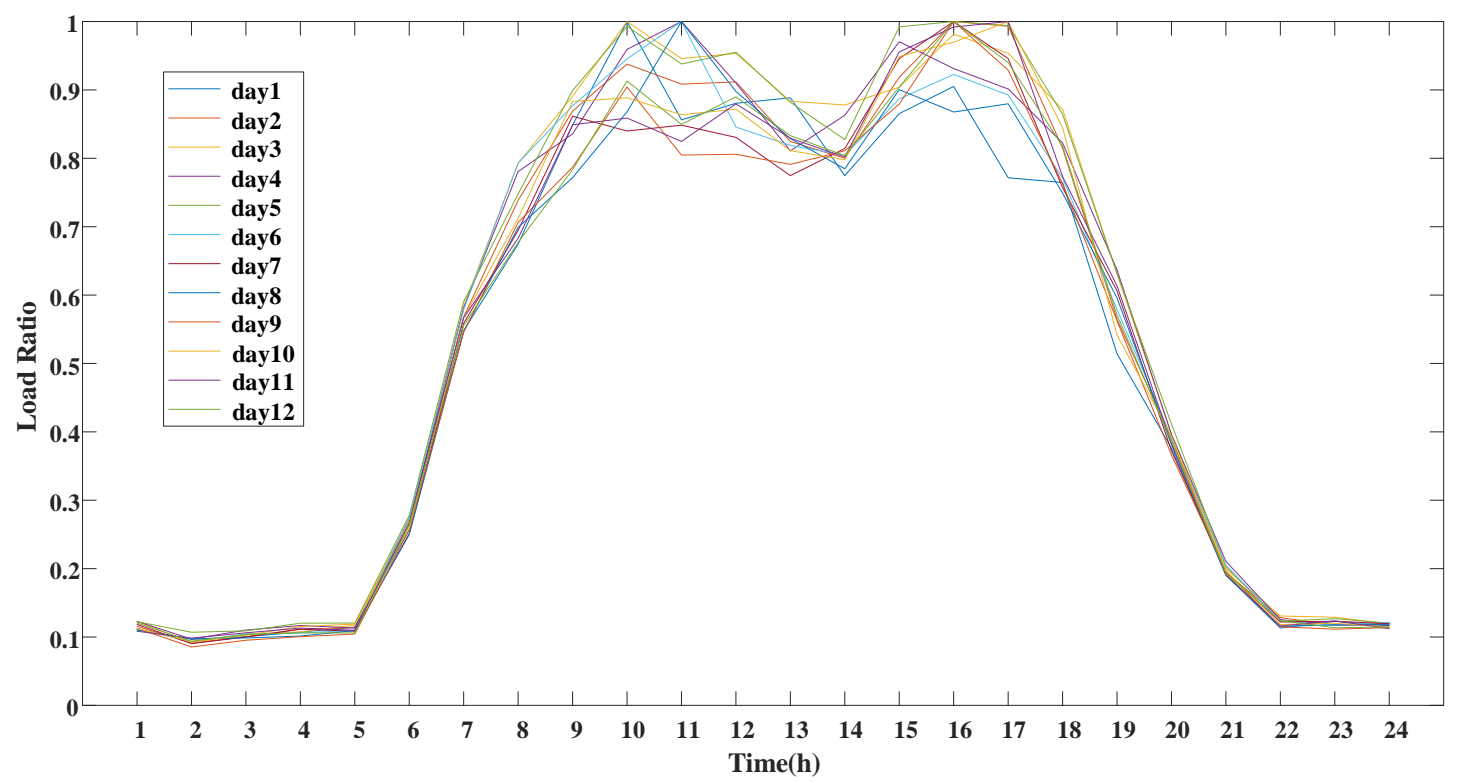

Figure 5. Load ratio curve of office type buildings at different days.

Figure 6 shows the load ratio curves at different times in commercial type buildings. The peak load period of this type mainly concentrated between 9:00 a.m. and 22:00 p.m. which coincides with the usual business hours in the business district. During business hours in business districts, shopping malls, entertainment facilities and restaurants need a large amount of electricity. When business areas are closed, there will be little electricity demand. Therefore, the peak and trough periods of the load ratio curves are obviously the same as the office type.

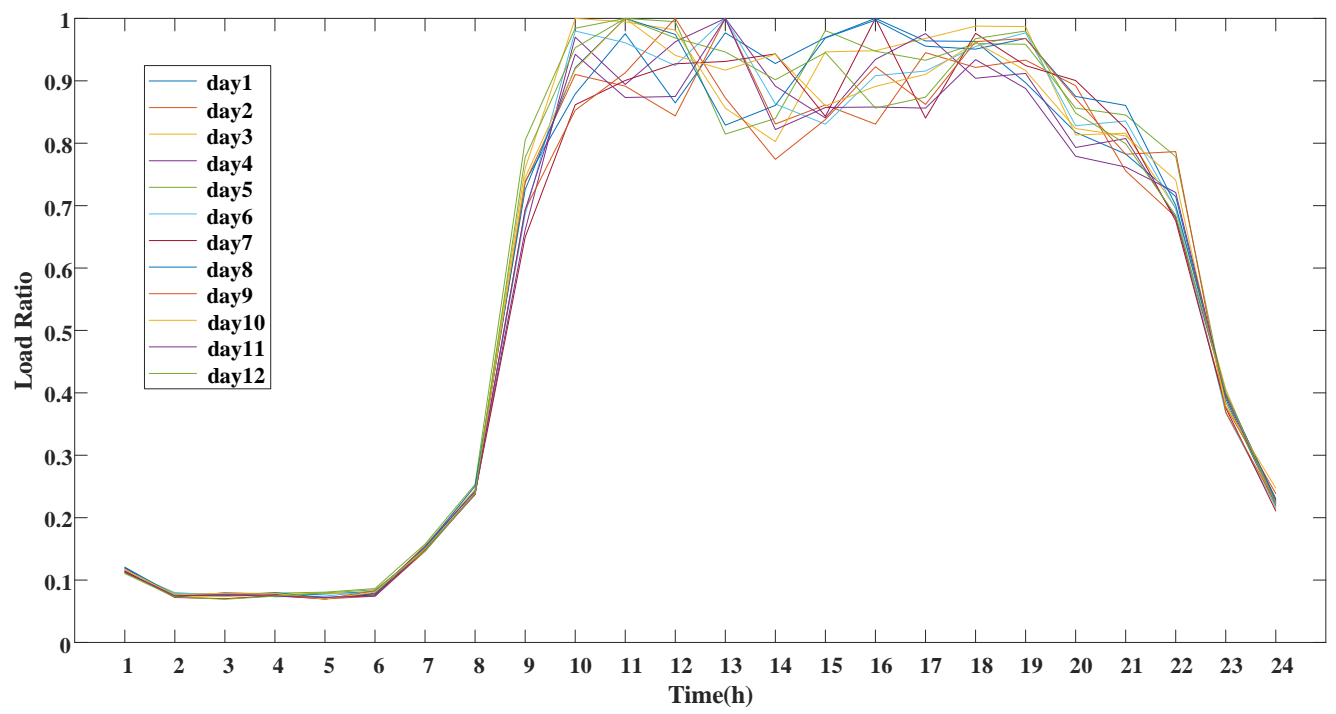

Figure 6. Load ratio curves of commercial type buildings at different days.

The typical load ratio curves of the different types are shown combined in Figure 7. The load ratio is obviously closely related to the activity hours of the different types of building. Especially in commercial and office type buildings, the peak load period is concentrated during business hours. The load ratio of the rest of the time is much lower than the peak period, which is not conducive to the operation of the power grid. 


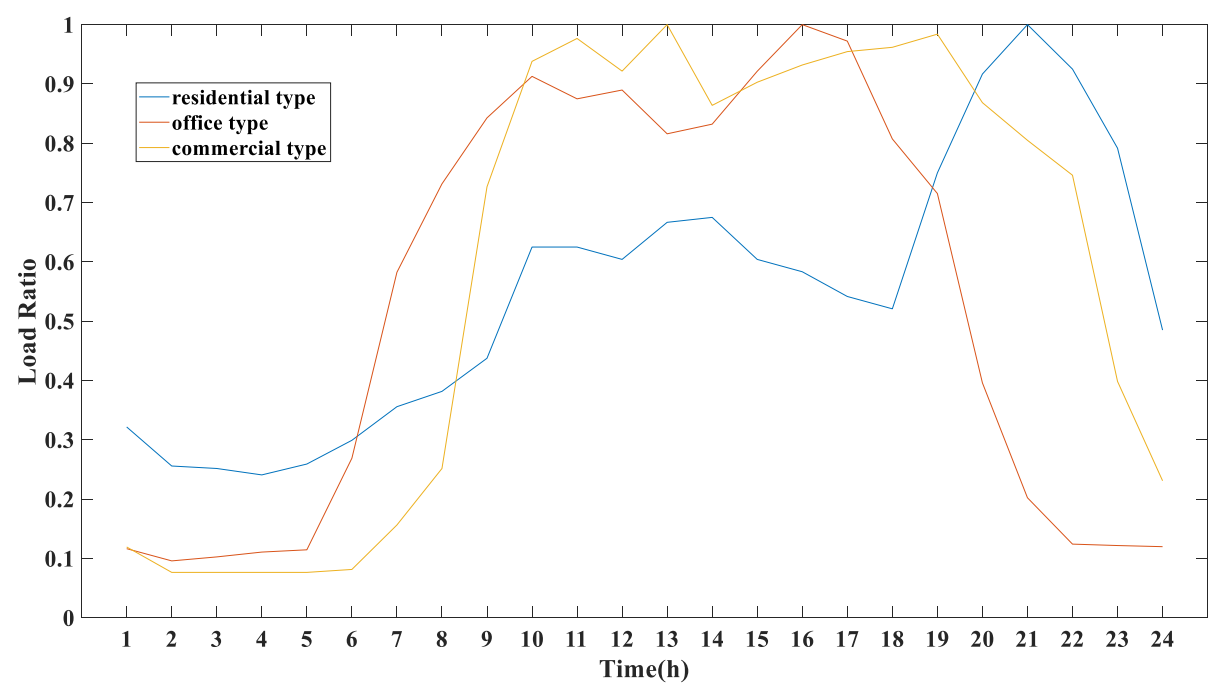

Figure 7. Typical load ratio curve of different building function types.

The overall load ratio $\alpha_{U C}^{T}$ can be calculated by the following expression:

$$
\alpha_{U C}^{T}=\frac{P_{\mathrm{UC}}^{T}}{P_{\mathrm{UC}}^{\max }}
$$

where $P_{\mathrm{UC}}^{T}$ is the power load at time $T, P_{\mathrm{UC}}^{\max }$ is the maximum power load in the day.

The overall load ratio of the UC is determined by the load ratio and maximum load of the building types, therefore, the proportion of different building types directly affects the overall load ratio. Developers' positioning to build UCs will determine the load ratio curve of the UC. Figure 8 shows the overall load ratio of a city complex. From Figure 8, it can be observed that the peak load period of the UC is still relatively concentrated, and the peak-valley difference is large.

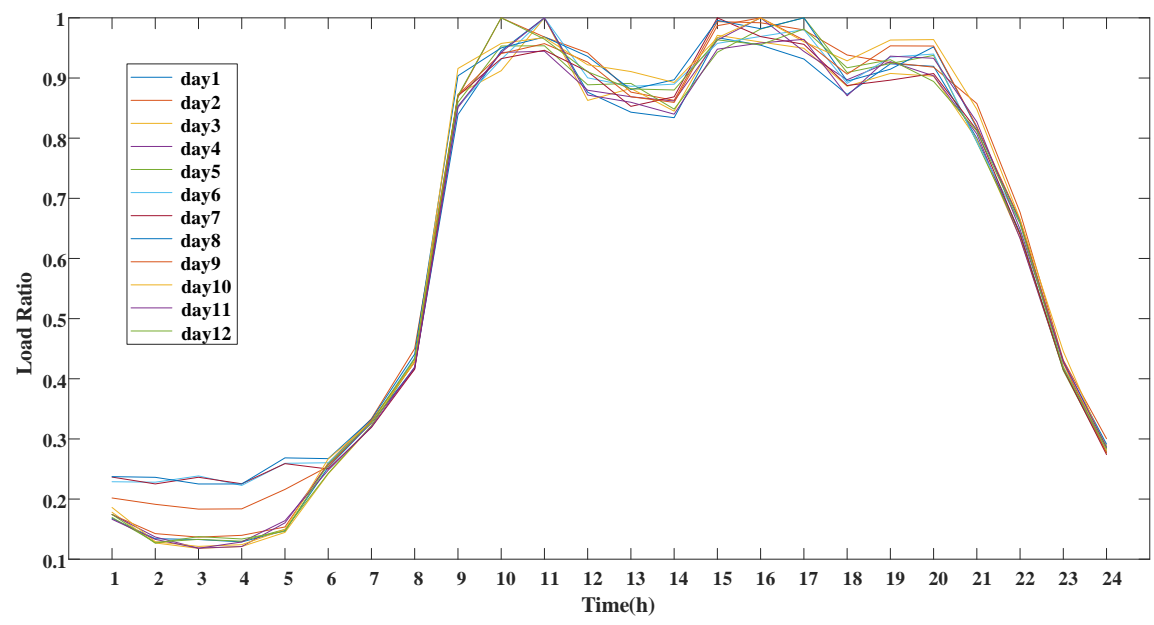

Figure 8. Load ratio curve of UCs at different days.

\subsection{Parking Behavior of UC}

The parking characteristics of commercial type, office type and residential type building in an UC are quite different. The peak parking time and parking turnover ratio are different in different UC building functional types. In order to analyze the parking characteristics more conveniently and accurately, we should find out the rules relating different parking characteristics and load 
characteristics [39]. There are three types of UC, so the parking ratios under these three types of UC are discussed separately.

The parking ratio $\alpha_{\text {park }}$ is defined as the ratio of the number of parking lots to the number of parking spaces provided by the garage per period.

$$
\alpha_{\text {park }}=\frac{N_{t}}{N_{\max }}
$$

where $N_{t}$ is the number of parking lots available at time $t$ and $N_{\max }$ is the total number of parking spaces in the garage

Figure 9 is a typical residential type parking ratio curve. The parking ratio of residential type buildings mainly depends on the habits of residents. Some residents drive to work during the day. After work, these residents drive home. Therefore, the probability of parking during the day is relatively low, while the ratio of parking at night is higher. Some families have more than one car, and some cars are used for other temporary trips besides work. These cars will be parked in the garage for long time during a day. Therefore, the parking ratio in residential areas is always high.

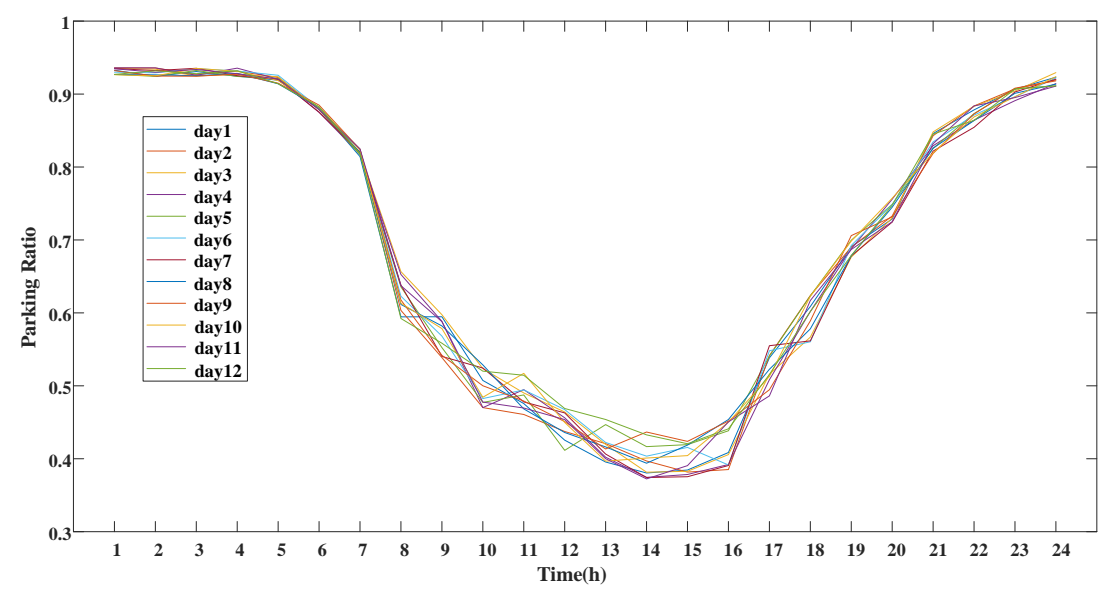

Figure 9. Typical parking ratio curves of residential type buildings at different days.

Figure 10 is a typical parking ratio curve of an office type building. Employees drive from home to work and leave their cars in the garage. Some of the employees go home for a rest or out for lunch, so there is a slight drop in parking at noon. The utilization ratio of the garage maintains at a high level during the working hours, and utilization ratio of the garage is very low during other periods.

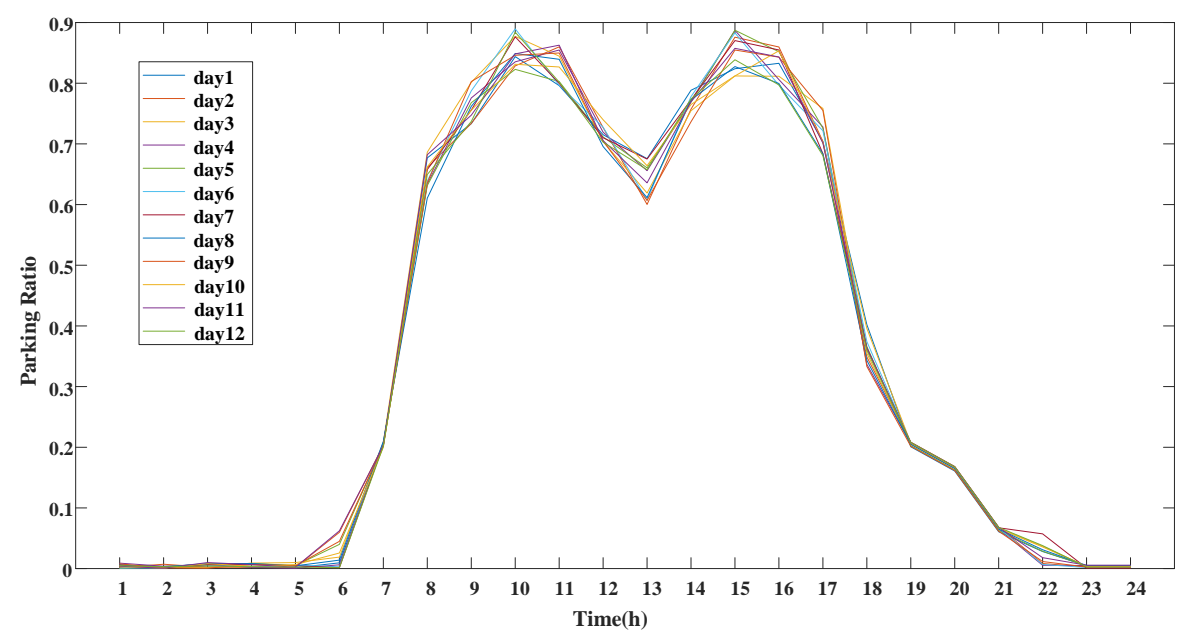

Figure 10. Typical parking ratio curve of office type at different days. 
Figure 11 shows typical parking ratio curves of a commercial type building. The parking characteristics of commercial format are related to many factors, such as pedestrian flow, position and development of the UC. At the early opening period of the UC, the parking demand is low because of the low business ratio. With the increase of business, the demand for parking spaces also increases. Overall, the parking ratio during opening hours is much higher than at other times. The parking ratio is at a very low level in other times, especially in the early morning.

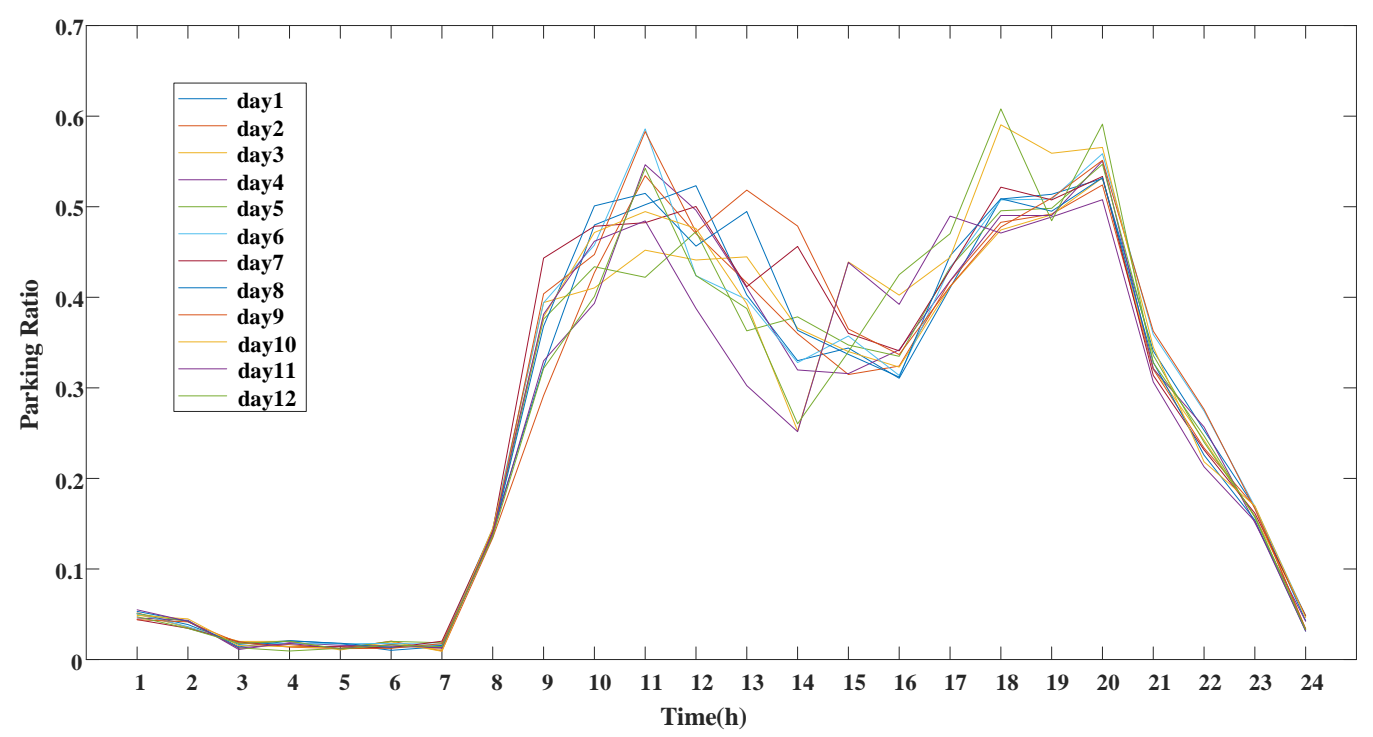

Figure 11. Typical parking ratio curves of commercial type buildings at different days.

We can observe that there is a strong correlation between the load characteristics and parking characteristics of office business and commercial business type buildings. The calculation and analysis of the load ratio and its corresponding parking ratio are carried out. The correlation coefficients of different dates are obtained in Table 3. There is a strong positive correlation between the load ratio and parking ratio of office type and commercial type buildings. Although the correlation coefficients of residential type buildings are low, the parking ratio of residential type buildings remains at a high level. Therefore, our research takes advantage of EVs as mobile energy storage terminals, and the correlation between parking ratio and load ratio of an UC, and presents the strategy of peak-shaving during the peak load time of the UC.

Table 3. Correlation between the load ratio and parking ratio of different function types.

\begin{tabular}{cccc}
\hline Date & Commercial & Office & Residential \\
\hline Day1 & 0.93026 & 0.960493 & -0.32142 \\
Day2 & 0.958525 & 0.95422 & -0.31743 \\
Day3 & 0.951995 & 0.95055 & -0.27929 \\
Day4 & 0.937235 & 0.953497 & -0.14804 \\
Day5 & 0.95543 & 0.953404 & -0.32844 \\
Day6 & 0.949204 & 0.957675 & -0.16634 \\
Day7 & 0.953815 & 0.950329 & -0.34091 \\
Day8 & 0.943993 & 0.951152 & -0.16013 \\
Day9 & 0.955598 & 0.95061 & -0.27576 \\
Day10 & 0.932579 & 0.953988 & -0.27335 \\
Day11 & 0.928337 & 0.944777 & -0.32217 \\
Day12 & 0.931294 & 0.946525 & -0.31062 \\
\hline
\end{tabular}




\section{Math Description and Control Strategy}

According to the analysis presented in the previous section, the market entry of large-scale UCs basically breaks the upper limit of the original urban grid planning. This will cause power shortages and equipment failures in some areas. The construction speed of large-scale UCs is usually very fast. Even if the grid projects that need supporting construction are synchronously set up to carry out preliminary work, they cannot be completed and put into operation when a large UC is put into use. It is often necessary to adopt emergency distribution network projects to complete the temporary transition of the power supply scheme. Large-scale UCs have high electricity consumption and large daily load peak-valley differences. If they blindly invest in power grid construction according to the maximum load requirements, it will inevitably lead to unnecessary waste of resources. In order to meet the multi-functional needs of the UC, we should support the construction and use of large garages to meet the parking demands of consumers. With the development of EVs, more and more EVs will replace petroleum fuel vehicles. Random charging of these EVs will also have a huge impact on the power grid, greatly increasing the risk of power grid accidents. In our research, the advantages of EVs as mobile energy storage terminals are put forward. According to the load and parking characteristics of the UC, a large UC garage can be used to control the charging of EVs in an orderly way, making them participate in the UC load control and solving the potential safety problems caused by the disorderly charging of EVs. The large daily load peak-valley differences of the UC cause the problem of excessive distribution network equipment resources [40], as well as the problem of lagging behind the planning of the power grid due to the large number of UCs.

In order to control the task conveniently and reduce the operation time and size of the necessary control center, our research proposes a two-tier real-time control strategy based on the EV user layer and the grid load decision-making layer. The lower layer divides the EVs into groups according to the load characteristics and parking characteristics of the UC, and then integrates the state information of the EVs in each group. We calculate the maximum electricity that can participate in the regulation in each regulation interval of each group. Due to the randomness of the behavior of EVs, the dynamic callable power of the first regulation period is updated continuously according to the changes in the number of EVs. The integration state information of each group calculated by the user layer will be send to the grid layer. The power grid decision-making level determines the power size of each group by formulating a dynamic target load curve according to the dynamic callable EV power of each group in each period. Thus, the load of the UC can be reduced to fill valleys and peaks. The upper decision is fed back to the lower. The lower level determines the charge power of each vehicle according to the power required by each group.

Aiming at EVs participating in load regulation of UC, our research puts forward the following main ideas:

(a) The users' willingness to participate in UC load control will be affected by battery status, periods of initial parking and other factors. Therefore, UC managers can specify price strategies to attract more users to participate in load control. Many scholars have studied the price strategy of $\mathrm{V} 2 \mathrm{G}$, and our research does not elaborate on this topic. When the user agrees to participate in load control, the load control center will collect the relevant data of the EVs to formulate a control strategy.

(b) The start parking period of EVs is random, and the parking requirement in the UC is large. If the new parked EV data is imported when each vehicle stops, the EV charging strategy will be changing constantly, which makes the strategy infeasible. Therefore, our research divides the peak period into equal time intervals. At the end of the last adjustment interval $(\mathrm{K}-1)$, the control strategy of the next interval $(\mathrm{K})$ is worked out. When EVs are parking in the T-interval, they will not participate in the load regulation of the K-interval. The EVs parking in T-interval will participate in the strategy formulation of the next $\mathrm{RI}(\mathrm{K}+1)$. This method can avoid the strategy from changing too frequently. 
(c) According to the analysis of different function types of UC, there are some typical parking characteristics of business type buildings such as short parking periods, high turnover ratio and large parking quantities. Although the total battery capacity which can participate in the strategy formulation is very large, most of them can't be controlled flexibly. They can only participate in the load control in their short parking period. As for office buildings, most of the parking periods are as long as the working hours, and the turnover ratio is low. That means they can be controlled flexibly. The parking ratio in residential type buildings is always at a high level. Therefore, the parking EVs of residential type can be controlled flexibly, so we use a large number of EVs in commercial type buildings for inflexible control, and EVs in office and residential type buildings for further flexible control.

(d) The number of parking EVs in the UC is large. In order to reduce the computational load of the control center, our research clusters the EVs in the UC according to the previous analysis. Parking EVs in commercial areas is mainly for consumers, whose initial parking time is random. We take them as a group. In order to ensure the availability if a suitable numbers of EVs that can participate in load regulation flexibly, we formulate preferential policies to attract and sign agreements with users with long parking time and low frequency in office type and residential type buildings. According to the parking period, those EVs in the UC are divided into office EV group and residential EV group. According to the parking characteristics, the EVs are divided into groups, and the group is taken as a whole to participate in the formulation of the strategy and get the total discharge power of each group in each RI. Then, the discharge of each group is allocated to each EV.

\subsection{Regulation Interval And EV Model}

According to Figure 8 and previous study on the load characteristics of UC, the peak load regulation period will be 9:00-22:00, so the peak load of the UC lasts 13 hours a day. The scheduling cycle is divided into several regulation intervals $\Delta t$ on average. Therefore, the number of RI in the peak load hour is:

$$
K=\frac{13}{\Delta t}
$$

The discharge strategy does not change in each regulation period. If $\Delta t$ is too small, the strategy changes quickly. The computation will be so complex that there is no enough time to work out the strategy. If $\Delta t$ is too long, the uncertainties of EV will increase during the regulation period, and less EV satisfy the $\Delta t$ parking period conditions [41]. The number of EVs that can participate in dispatching decreases, which affects the total battery capacity provided for the UC.

When the EV parks in the garage, the control center will collect the state information represented by $\Gamma$

$$
\Gamma=\left[I D_{E V} T_{\text {arrive }} T_{\text {leave }} S O C_{\text {arrive }} S O C_{\text {leave }} L\right]
$$

where $I D_{E V}$ is the car number of an EV; $T_{\text {arrive }}$ is the time when the car arrives at the UC; $T_{\text {leave }}$ is the time for leaving the UC; $S O C_{\text {arrive }}$ is remaining SOC of EVs parking at $k$-interval; $S O C_{\text {leave }}$ is the SOC when a user leaves the garage; $L$ represents which functional areas the EV belong and whether the car participates in discharge control.

When the EV is parked in the garage, the garage dispatching system will collect the status information of the vehicle. At the same time, the user's willingness to participate in load regulation is sought [42]. Users willing to participate in load regulation will be required to input the earliest time they plan to leave the garage and the minimum target power when the user leaves.

According to the state information of the car, the parking period $T_{\text {park }}(n)$ and the maximum capacity $S O C_{\text {con }}(n)$ providing for UC of the $n$-th EV can be obtained by using Equations (10) and (11):

$$
T_{\text {park }}(n)=T_{\text {leave }}-T_{\text {arrive }}
$$




$$
\operatorname{SOC}_{\text {con }}(n)=S O C_{\text {arrive }}-S O C_{\text {leave }}
$$

As shown in Figure 12. $T_{\text {avai }}(n)$ is the regulation interval which the $n$-th EV can participate in. It can be calculated as follows:

$$
T_{\text {avai }}(n)=T_{\text {leave }}-T_{\text {arrive }}
$$

where, $T_{\text {leave }}$ means the beginning time of the control period interval not greater than $T_{\text {leave, }}$, and $T_{\text {arrive }}$ means the end time of the control period interval not less than $T_{\text {arrive }}$.

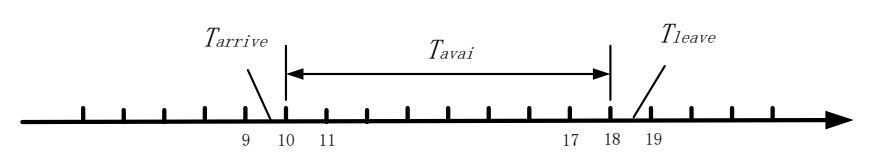

Figure 12. The regulation interval that the EV can participate in.

The garage parking information matrix of the $k$-th interval $\Lambda^{k}$ can be obtained from the parking state information of vehicles and for the further application:

$$
\Lambda^{k}=\left[\begin{array}{ccc}
\Gamma_{1}^{1} & \Gamma_{2}^{1} & \cdots \\
\Gamma_{1}^{2} & \ddots & \\
\vdots & & \Gamma_{i}^{k}
\end{array}\right]
$$

\subsection{Clustering of EVs}

EVs are divided into three groups based on the analysis of Section 2:

(1) The first type is the EVs parked in residential type of UC buildings and contracted with the control center. The vehicles will park in the garage most of the time, which always keeps a high parking ratio in the garage. These cars are parked in garages most of the day and have shorter travel times plus shorter distances. They can be observed as a dynamic balanced whole part. They can participate in load regulation during the peak load period. By signing a contract with the owner, the control center can get the total amount of electricity of EVs in advance and take them as a whole part. We define those EVs as Group A.

The control center gets the target SOC of each user set by the contract and calculates the controllable electricity. Then, the maximum total controllable electricity of Group A in a day is obtained by adding up that of each EV. Considering that some EVs will leave temporarily during peak load period, we define $S A_{\text {total }}$ as the controllable electricity of group A participating in regulation in one day which can be obtained by multiplying a coefficient on the total electricity:

$$
S A_{\text {total }}=\eta \cdot \sum C(n) \cdot\left(S O C A_{\text {start }}(n)-S O C A_{\text {target }}(n)\right)
$$

where, $C(n)$ is the battery capacity of the $n$-th EV; $S O C A_{\text {start }}(n)$ is the $n$-th EV's SOC of starting parking and $\operatorname{SOCA}_{\text {target }}(n)$ is the target SOC set by the EV owner.

(2) The second type is the EVs parked in office type buildings and contracted with the control center. The parking period of these contracted EVs is the same as the working hours. Therefore, the time for these vehicles to participate in load regulation is working hours. These vehicles are classified as Group B. In the paper, the regulation period of Group B is 9:00-18:00. Before 9:00 a.m., the cars will be parked in the garage. We define $S B_{\text {total }}$ as the total electricity involved in the regulation according to the target SOC set by the users:

$$
S B_{\text {total }}=\eta \cdot \sum C(n) \cdot\left(S O C B_{\text {start }}(n)-S O C B_{\text {target }}(n)\right)
$$


(3) The third type is the EVs parked in commercial type building garages. The starting parking time and parking period of these vehicles are related to the purpose of consumers going to the UC. The number of cars parked is large, but we cannot estimate the number of cars parked in each RI accurately. When the vehicle stops in the (K-1)-interval, the control center will inquire about the owners' willingness to participate in load regulation. For the vehicles involved in the regulation, the electricity of each vehicle in K-interval is calculated according to Equations (8) and (11), and we define $S C_{\text {total }}^{k}$ as the total controllable electricity of Group C in the $k$-th RI which can be obtained by adding up the electricity of each vehicle parked in the $k$-th RI:

$$
S C_{\text {total }}^{k}=\eta \cdot \sum C(n) \cdot\left(\operatorname{SOCC}_{\text {start }}(n)-\operatorname{SOCC}_{\text {target }}(n)\right)
$$

\subsection{Objective Function And Constraints}

The electricity of group $C$ has been determined in each RI and cannot be controlled. The controllable total electric quantity of group A and group B during peak load periods need to be determined as well. We define that $P^{k}$ represents the conventional load after subtracting the discharge power in the $k$-th interval. $P_{A}^{k}$ and $P_{B}^{k}$ represent the total discharge capacity of group A and group B in the $k$-th interval. They can be decided by the objective function Equation (17) which minimizes the mean square deviation of load [43].

$$
F=\min \frac{1}{22 / \Delta t-k} \sum_{k}^{K}\left(P^{k}-P_{B}^{k}-P_{A}^{k}\right)^{2}
$$

The discharge power of each EV participating in load regulation should be within the threshold power allowed in the garage. The total amount of discharge electricity in each RI of each vehicle is not greater than the total controllable electricity. At the same time, the electric quantity of each vehicle in each RI is not greater than the total electricity, that is:

$$
\left\{\begin{array}{l}
P A^{k}(n), P B^{k}(n) \leq P_{\max } \\
22 / \Delta t \\
\sum_{k=1+9 / \Delta t} \Delta t \cdot P A^{k}(n) \leq S A(n) \\
\sum_{n=1}^{N_{A}} \sum_{n=1+9 / \Delta t}^{22 / \Delta t} \Delta t \cdot P A^{k}(n) \leq S A_{\text {total }} \\
18 / \Delta t \\
\sum_{k=1+9 / \Delta t} \Delta t \cdot P B^{k}(n) \leq S B(n) \\
\sum_{n=1}^{N_{B}} \sum_{k=1+9 / \Delta t}^{18 / \Delta t} \Delta t \cdot P B^{k}(n) \leq S B_{\text {total }}
\end{array}\right.
$$

where $P_{\max }$ is the threshold power allowed in the garage; $N_{A}$ is the number of EVs in Group A; $P A^{k}(n)$ is $n$-th EV's discharge power in the $k$-th RI of Group A; $S A(n)$ is the $n$-th EV's total controllable electricity in Group A; $N_{B}$ is the number of EVs in Group B; $P B^{k}(n)$ is the $n$-th EV's discharge power in the $k$-th RI of Group B and $S B(n)$ is the $n$-th EV's total controllable electricity in Group B.

\subsection{Discharge Power of Each EV}

After getting the total discharge electricity of Group A and Group B in each RI, the discharge electricity will be allocated to each EV. When the EV's power is less than the average value of discharge, the vehicle will discharge all the electricity during the RI. The discharge power of the other EVs is the 
average power of the vehicles excluded from the EVs whose power is less than the average value [44]. Taking group A as an example, the average discharge power $P A_{a v e}^{k}$ in the $k$-th $\mathrm{RI}$ is:

$$
P A_{\text {ave }}^{k}=\frac{S A_{t o t a l}^{k}}{\Delta t \cdot N_{A}^{k}}
$$

where $S A_{\text {total }}^{k}$ is the total electricity in Group A that will discharge in the $k$-th RI, $N_{A}^{k}$ is the number of Group A EVs in the $k$-th RI.

We define that $S A_{\text {total }}^{k}(n)$ is the controllable electricity of the $n$-th EV in the $k$-th RI and $P A^{k}(n)$ is the discharge power of the $n$-th EV in the $k$-th RI.

If:

$$
S A_{\text {con }}^{k}(n)<\Delta t \cdot P A_{\text {ave }}^{k}
$$

then:

$$
P A^{k}(n)=\frac{S A_{c o n}^{k}(n)}{\Delta t}
$$

otherwise:

$$
P A^{k}(n)=\frac{S A_{\text {total }}^{k}-\sum S A_{\text {con }}^{k \prime}(n)}{\Delta t \cdot\left(N_{A}^{k}-N_{A}^{k \prime}\right)}
$$

where $S A_{\text {con }}^{k \prime}(n)$ is the controllable electricity of Group A in the $k$-th RI excluding the EVs whose power is less than $P A_{\text {ave }}^{k}$ and $N_{A}^{k \prime}$ is the number of EVs whose power is less than $P A_{\text {ave }}^{k}$.

The discharge power allocation of Group B $\left(P B^{k}(n)\right)$ is the same as that of Group A, so it will not be discussed repeatedly in our research.

In order to maximize the available electricity in Group $C$ to participate in the regulation, the EVs in Group $C$ will feed back to the UC with the maximum discharge power until the EV leaves or the remaining $\mathrm{SOC}$ reaches the target.

We define $P C^{k}(n)$ as the discharge power of the $n$-th EV in group C in the $k$-th RI. It can be calculated by the following expression:

$$
P C^{k}(n)=\frac{S C_{c o n}^{k}(n)}{\Delta t}
$$

If:

$$
P C^{k}(n) \geq P_{\max }
$$

then, the discharge power is decided by $P_{\max }$

$$
P C^{k}(n)=P_{\max }
$$

Based on the above mathematical description, the load regulation strategy can be briefly summarized as follows. Firstly, we divide peak load period into several regulation intervals $\Delta t$ on average, and get the garage parking information matrix $\Lambda^{k}$, and then, we calculate the parking period $T_{\text {park }}(n)$ and the maximum capacity $S O C_{\text {con }}(n)$ of each EV. Secondly, EVs are divided into three groups and the total controllable electricity $S A_{\text {total }}$ and $S B_{\text {total }}$ and uncontrollable electricity $S C_{\text {total }}^{k}$ in each RI can be calculated by $\Lambda^{k}$. Thirdly, we set the total discharge power of group A and group $B$ in each RI $\left(P_{A}^{k}\right.$ and $\left.P_{B}^{k}\right)$ as the decision variables, and then, set the objective function as Equation (17) and constraints as Equation (18). Finally, calculate the discharge powers $P A^{k}(n), P B^{k}(n)$ and $P C^{k}(n)$ of each $\mathrm{EV}$ in the different groups in each RI. 


\section{Case Analysis}

\subsection{Case Statement}

Our study chooses an UC as the research object, which integrates the functions of commercial retail, business offices, hotel catering, comprehensive entertainment facilities and apartment housing as a whole thing. It covers an area of 360,000 square meters and consists of a commercial building, four residential buildings and an office building. The parking space can hold 2000 vehicles, and 500 vehicles can be charged and discharged here now. The typical conventional daily load of the UC is shown as Figure 13.

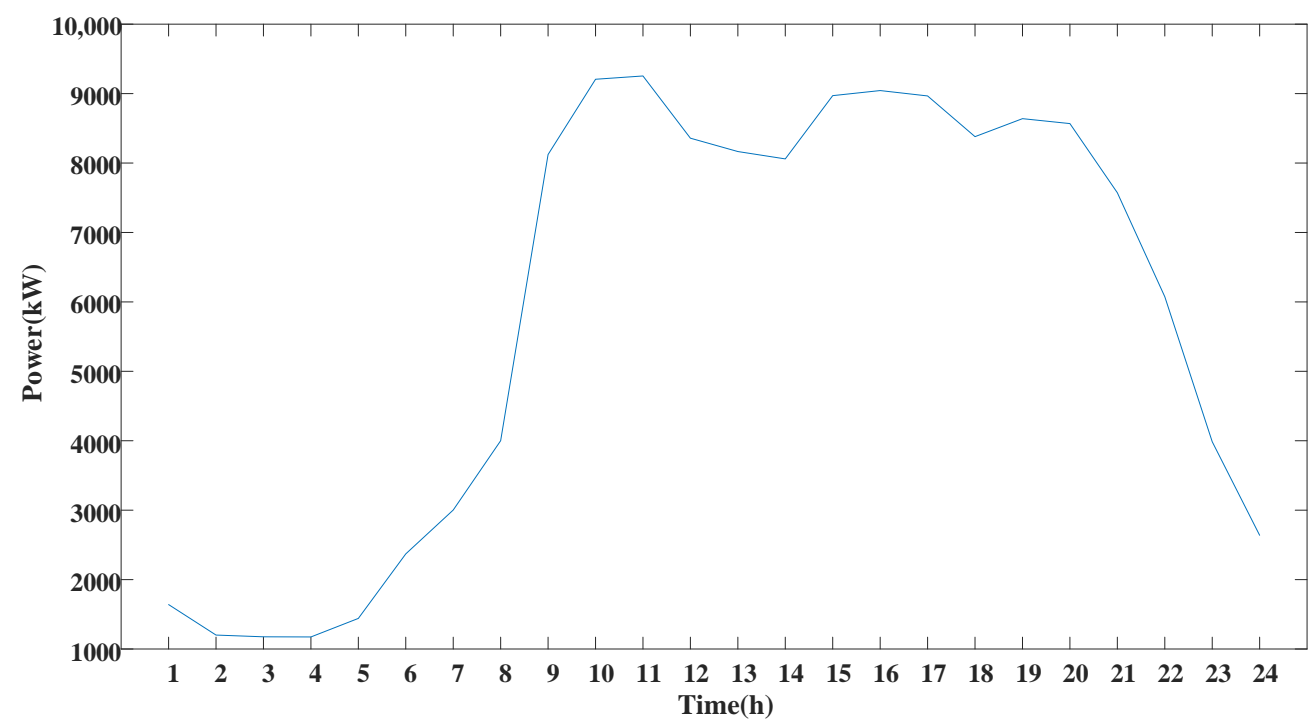

Figure 13. Typical conventional grid load of a UC.

At present, the proportion of EVs is still very low compared with traditional vehicles. We assume that 50 office EVs agree to establish a contract to participate in the load regulation during working hours and 50 household EVs participate as well. The number of EVs entering the commercial type area is 4000 a day. The parking characteristics of Group C are randomly generated by using the typical parking ratio fitting curve of commercial type buildings analyzed in Section 2. Suppose the initial SOC of each EV starting discharging in the garage meets a normal distribution $\mathrm{N}(0.65,0.05)$.

\subsection{Influence of The Permeability}

The scale of Group C is large, so the permeability of EVs is an important factor affecting the efficiency of the strategy. We assuming that the length of the RI is set to be $30 \mathrm{~min}$, and we change the different permeabilities for Group C. When there is no group A and group B involved in the regulation, the impact of EVs participating in UC load regulation with different peak load permeabilities is shown in Figure 14. It can be observed from the figure that peak load decreases with the increase of permeability of EVs. EVs in Group C can relieve the peak load pressure. However, group C loads cannot be regulated. As shown in Figure 14, load reduction is obvious in the evening when the parking time of group $\mathrm{C}$ is concentrated. However, the effect of load regulation is poor at noon when the number of vehicles in group $C$ is small. It is the reason why peak load decreases about to $9.43 \%$ when the permeability reaches $100 \%$.

The effects of load regulation are obviously improved as shown in Figure 15 when group A and group B EVs participate. Group A and Group B EVs can discharge more power if the load is high and discharge less or no power if the power load is low. When the permeability reaches $100 \%$, the peak load decreases by $14.25 \%$, and the peak load becomes more stable. 


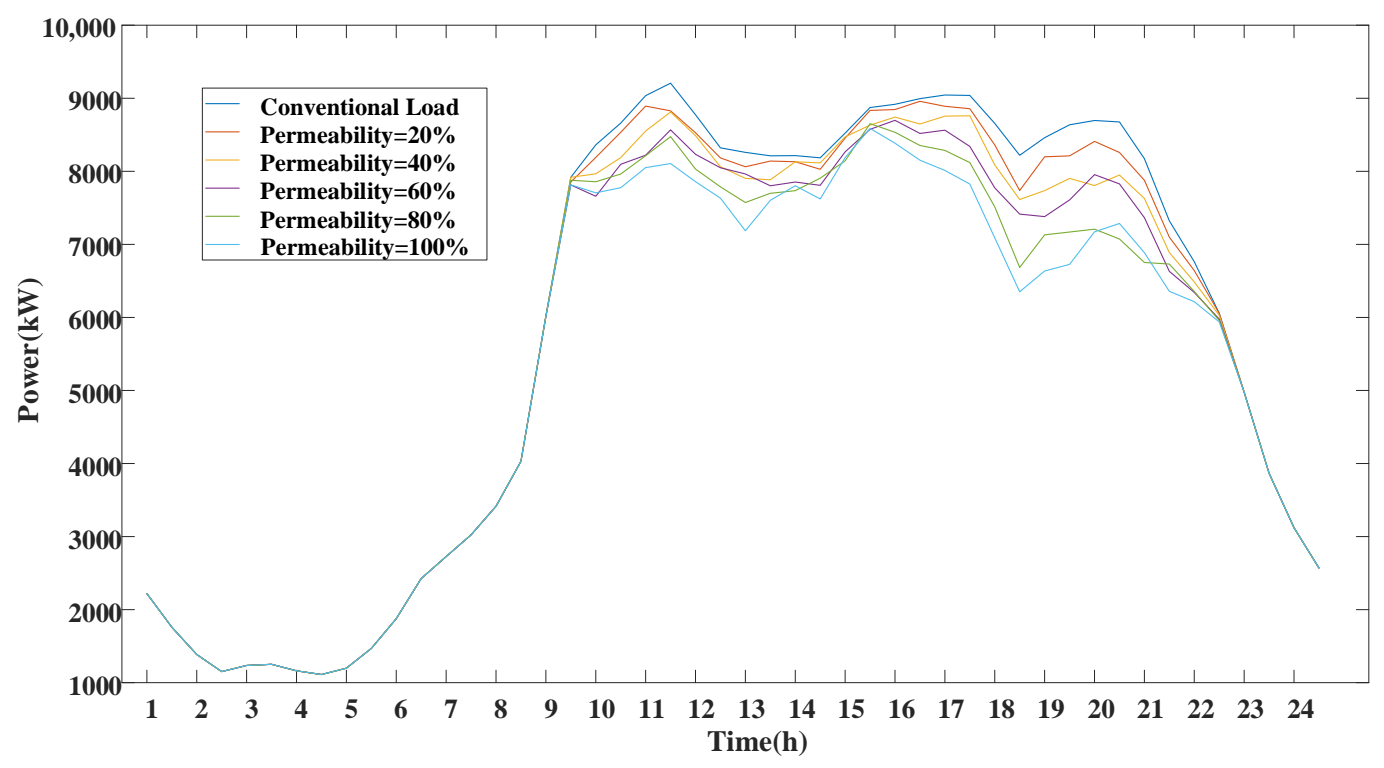

Figure 14. The load when only group C EVs participate in load regulation with different permeabilities.

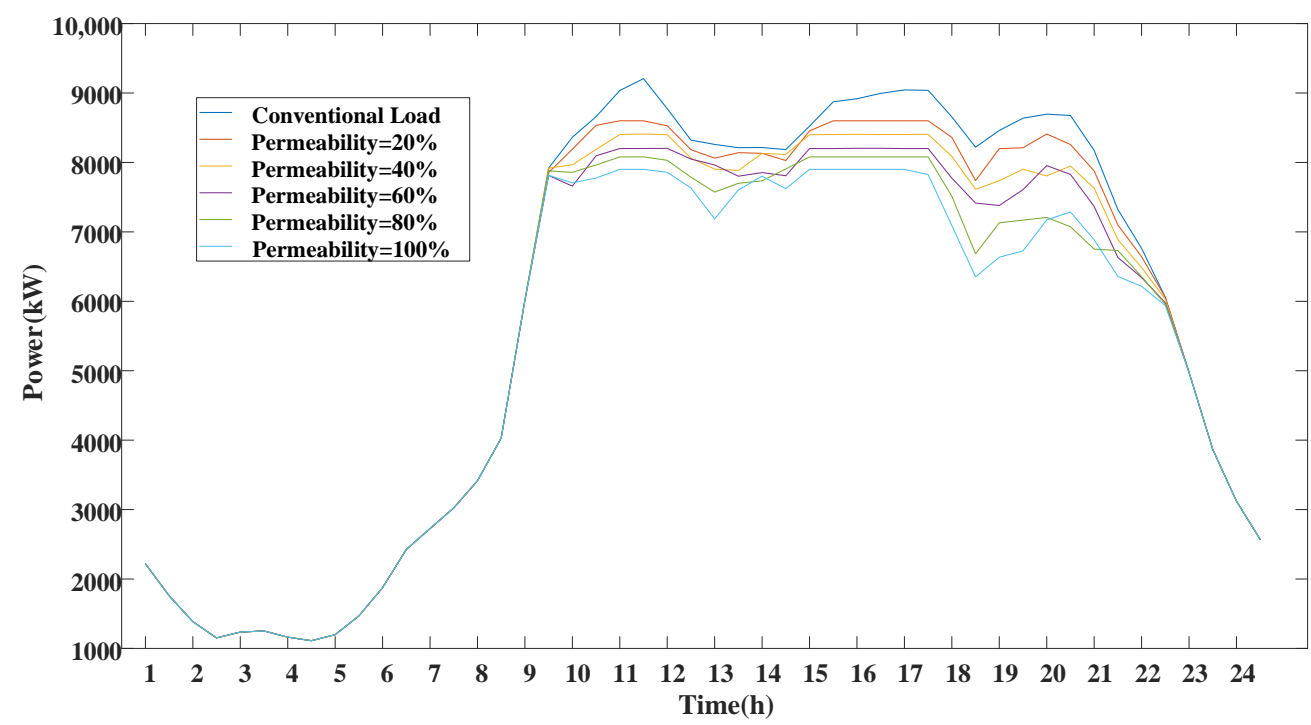

Figure 15. The load when group A,B and C EVs participate in load regulation with different permeabilities.

The load of UCs can be reduced effectively by increasing the permeability of EVs, although the permeability of EVs is still very low at present, and the peak load reduction is limited. However, with the increase of EVs' popularity and permeability, this strategy will play an important role in improving the load situation of UCs. It is very effective to reduce the peak load of UC by this strategy.

\subsection{Influence of The Regulation Interval}

Another influence on the effect of load regulation strategy is the length of RI. If the RI is too long, the parking period in the garage of EVs cannot meet the length of RI. The number of EVs of Group C participating in load regulation will be reduced greatly. If the length of RI is too short, the frequency of the strategy formulation will increase, which will increase the operational burden of the control center.

Assuming that the permeability of Group C is $40 \%$, we set the RI as 15, 30 and $60 \mathrm{~min}$, and explore the influence of different interval lengths when only group C EVs participate in load balancing. The simulation results are shown in Figure 16. When the RI is too long (60 min), the number of EVs that can satisfy the RI is very small, and it has little effect on load regulation. When the regulation 
time is shortened to $15 \mathrm{~min}$, load regulation strategy works well. The peak load decreases about $9.44 \%$, which is same as the situation ( $\mathrm{RI}=30 \mathrm{~min}$, permeability $=40 \%$, without Group A and B EVs). The shorter interval makes more EVs participate in the discharge, so that more electricity from Group C EVs can participate in the regulation.

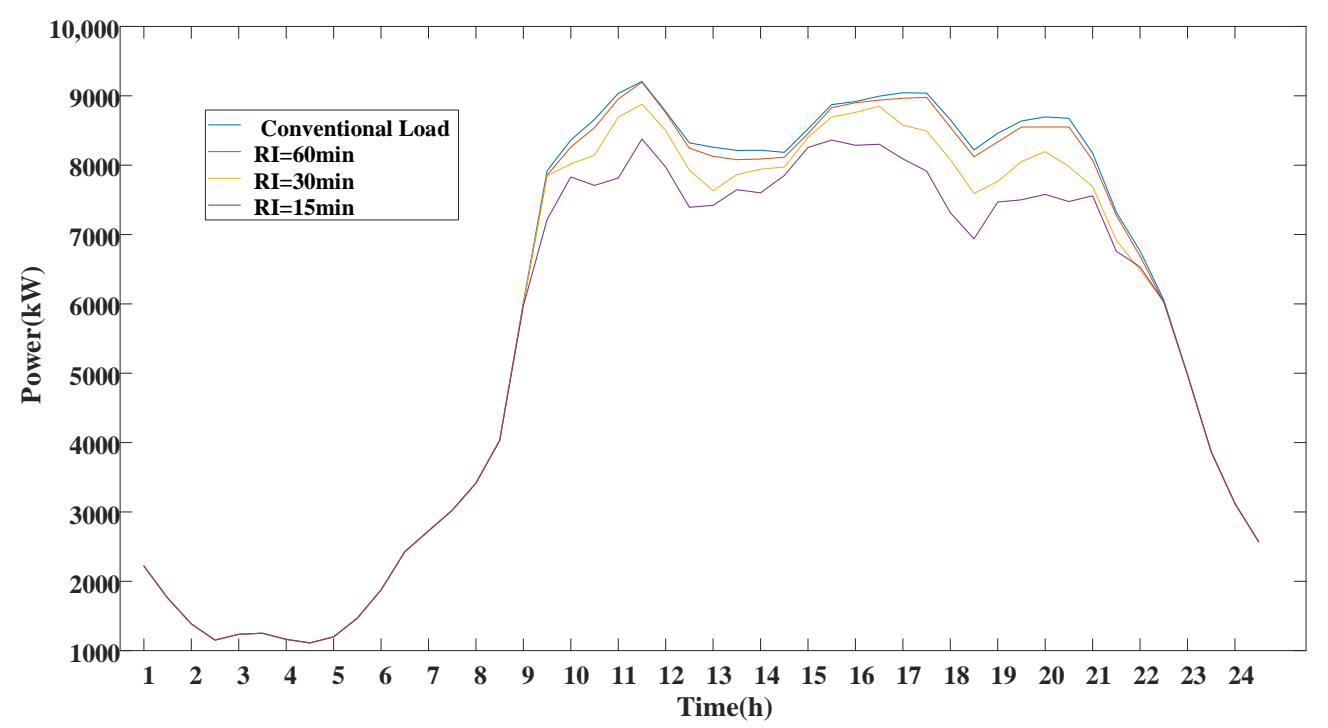

Figure 16. The load when only group C EVs participate in load regulation with different RIs.

As shown in Figure 17, when group A and group B EVs participate in load regulation, the peak load is further reduced by $14.6 \%$. The numbers of EVs of group A and B that participate in load regulation is relatively small compared with Group C ones. However, they still play an important role in peak load reduction and load fluctuation reduction. From the simulation results, this strategy can effectively reduce the peak load. Therefore, in the construction of an UC, less money will be spent in the transformation of the local distribution system and the operation of the local power grid will be safer.

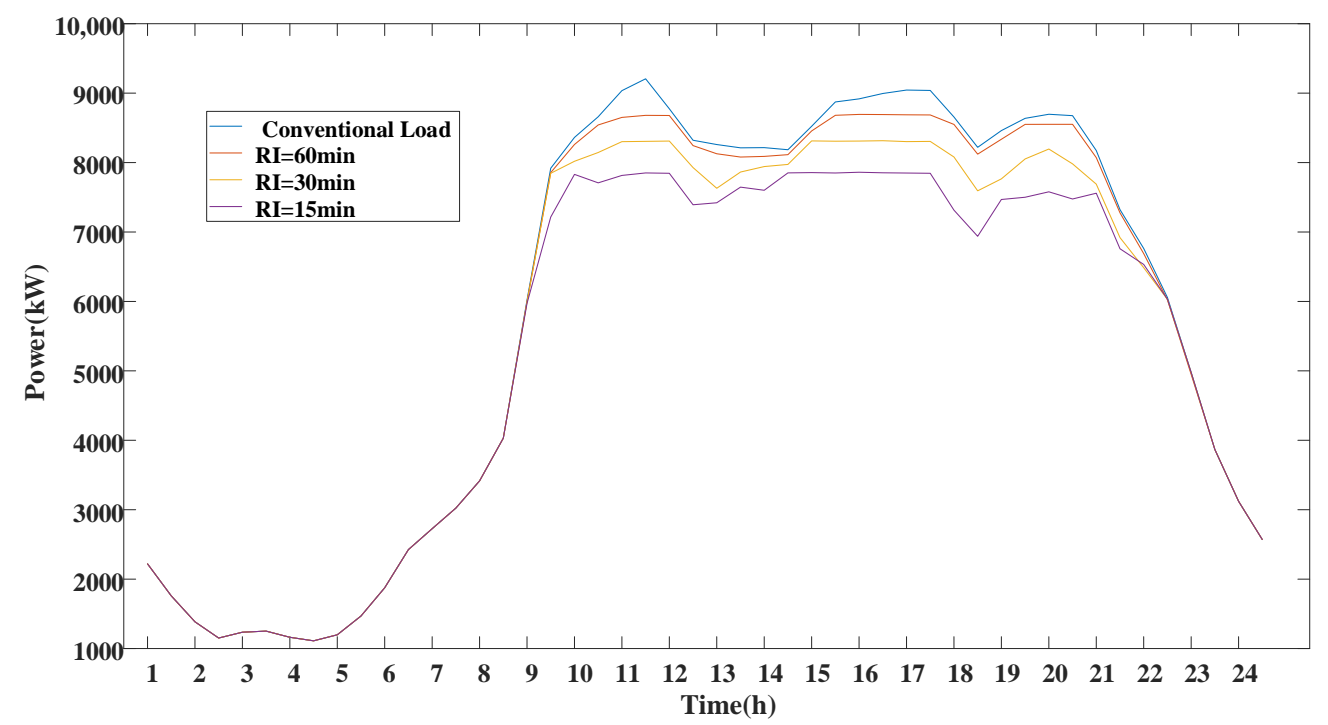

Figure 17. The load group when $A, B$ and C EVs participate in load regulation with different RIs.

However, when the length of the interval is short enough, the number of EVs that can participate in the discharge will not change anymore. Shortening the interval length will no longer optimize the 
load curve regulation of the UC, but will increase the operational load of the control center. Therefore, it is important to adopt an appropriate RI length in any load regulation strategy. The actual position and operational location of UC are different, so the parking characteristics of cars are different, which means the best RI length is different. It is necessary to determine the optimum RI length by analyzing the actual parking characteristics.

\section{Conclusions}

During the construction of an UC, due to the huge power consumption during peak periods, the capacity of power distribution equipment is high, and it is often necessary to transform the nearby power facilities, which will increase construction and maintenance costs. The popularity of EVs can improve the environment, but the stochastic large-scale charging of cars may pose a threat to the regional grid [45]. In view of the above problems, a strategy for EVs participating in load regulation of a UC was proposed. The stochastic charging load of EVs was modeled according to the users' habits. It was verified that the peaks of charging load and conventional loads will be superimposed. This situation may have a bad influence on the operation of the power grid. Because it is difficult to put forward a load regulation strategy if an UC is regarded as a whole, we divide UCs into different functional areas. The relationship between parking ratio and load ratio was obtained after dividing UCs into different functional areas. There are large numbers of vehicles in the commercial functional areas with high mobility (Group C), and vehicles in office and functional areas with low mobility (Group A and B). Then, we formulate the load regulation strategy: we divide the peak load period into several equal RIs, and establish a the parking information database. The EVs in group C of each RI will feed back to UC with maximum discharging power. The objective function was established to minimize load variance during the peak period of the UC, and the discharge power of Group A and B EVS of each RI was calculated by an objective function. Finally, the case analysis proved that the strategy in our research can effectively reduce the load of the UC during the peak load period. The results show that with the increase of the permeability, the number of EVs participating in load regulation also increases, which means more electricity from EVs is fed back to the UC to make the peak load smaller. Shortening the RI can make more vehicles from group C participate in load regulation and also improve the effect of load regulation. In the future, the strategy of charging EVs in UCs during valley load period will be studied to reduce the peak-valley load difference of the UC and improve the energy utilization structure of the UC. Considering that EVs can be used as mobile power sources, the characteristics of vehicles parked in the UC are analyzed in depth.

Author Contributions: All authors contributed equally to conceptualization, methodology development, software implementation, validation, formal analysis, investigation, writing-original draft preparation, writing-review and editing, visualization, and supervision. All authors have read and agreed to the published version of the manuscript.

Funding: This research was funded by the Chongqing Science and Technology Commission of China under Project No. cstc2018jcyjA3148; graduate scientific research and innovation foundation of Chongqing, China under Grant No. CYS1807; graduate research and innovation foundation of Chongqing, China under Grant No. CYB18009.

Conflicts of Interest: The authors declare no conflict of interest.

\section{References}

1. Li, G.; Zhang, X.-P. Modeling of Plug-in Hybrid Electric Vehicle Charging Demand in Probabilistic Power Flow Calculations. IEEE Trans. Smart Grid 2012, 3, 492-499. [CrossRef]

2. Shafiee, S.; Fotuhi-Firuzabad, M.; Rastegar, M. Investigating the Impacts of Plug-in Hybrid Electric Vehicles on Power Distribution Systems. IEEE Trans. Smart Grid 2013, 4, 1351-1360. [CrossRef]

3. Shafiei, E.; Thorkelsson, H.; Asgeirsson, E.I.; Davíðsdóttir, B.; Raberto, M.; Stefansson, H. An agent-based modeling approach to predict the evolution of market share of electric vehicles: A case study from Iceland. Technol. Forecast. Soc. Chang. 2012, 79, 1638-1653. [CrossRef] 
4. Clement-Nyns, K.; Haesen, E.; Driesen, J. The Impact of Charging Plug-In Hybrid Electric Vehicles on a Residential Distribution Grid. IEEE Trans. Power Syst. 2009, 25, 371-380. [CrossRef]

5. Amini, M.H.; Kargarian, A.; Karabasoglu, O. ARIMA-based decoupled time series forecasting of electric vehicle charging demand for stochastic power system operation. Electr. Power Syst. Res. 2016, 140, 378-390. [CrossRef]

6. Kevin, M.; Verschueren, T.; Haerick, W. Optimizing smart energy control strategies for plug-in hybrid electric vehicle charging. In Proceedings of the Network Operations \& Management Symposium Workshops, Osaka, Japan, 19-23 April 2010.

7. Zhong, J.; He, L.; Li, C.; Cao, Y.; Wang, J.; Fang, B.; Zeng, L.; Xiao, G. Coordinated control for large-scale EV charging facilities and energy storage devices participating in frequency regulation. Appl. Energy 2014, 123, 253-262. [CrossRef]

8. Sun, B.; Huang, Z.; Tan, X.; Tsang, D.H.K. Optimal Scheduling for Electric Vehicle Charging with Discrete Charging Levels in Distribution Grid. IEEE Trans. Smart Grid 2016, 9, 624-634. [CrossRef]

9. Donadee, J.; Ilic, M.D. Stochastic Optimization of Grid to Vehicle Frequency Regulation Capacity Bids. IEEE Trans. Smart Grid 2014, 5, 1061-1069. [CrossRef]

10. Pavić, I.; Capuder, T.; Kuzle, I. Value of flexible electric vehicles in providing spinning reserve services. Appl. Energy 2015, 157, 60-74. [CrossRef]

11. Chenye, W.; Hamed, M.R. PEV-based combined frequency and voltage regulation for smart grid. In Proceedings of the IEEE Pes Innovative Smart Grid Technologies IEEE Computer Society, Washington, DC, USA, 16-20 January 2012.

12. Zhou, C.; Qian, K.; Allan, M.; Zhou, W. Modeling of the Cost of EV Battery Wear Due to V2G Application in Power Systems. IEEE Trans. Energy Convers. 2011, 26, 1041-1050. [CrossRef]

13. Asensio, M.; Contreras, J. Stochastic Unit Commitment in Isolated Systems with Renewable Penetration under CVaR Assessment. IEEE Trans. Smart Grid 2015, 7, 1356-1367. [CrossRef]

14. Psarros, G.N.; Nanou, S.; Papaefthymiou, S.V.; Papathanassiou, S.A. Generation scheduling in non-interconnected islands with high RES penetration. Renew. Energy 2018, 115, 338-352. [CrossRef]

15. Thomas, D.; Deblecker, O.; Ioakimidis, C.S. Optimal design and techno-economic analysis of an autonomous small isolated microgrid aiming at high RES penetration. Energy 2016, 116, 364-379. [CrossRef]

16. Muñoz, E.R.; Razeghi, G.; Zhang, L.; Jabbari, F. Electric vehicle charging algorithms for coordination of the grid and distribution transformer levels. Energy 2016, 113, 930-942. [CrossRef]

17. Wang, L.; Sharkh, S.; Chipperfield, A.; Chipperfield, A.J. Optimal coordination of vehicle-to-grid batteries and renewable generators in a distribution system. Energy 2016, 113, 1250-1264. [CrossRef]

18. Huang, S.; Yang, J.; Li, S. Black-Scholes option pricing strategy and risk-averse coordination for designing vehicle-to-grid reserve contracts. Energy 2017, 137, 325-335. [CrossRef]

19. Graabak, I.; Wu, Q.; Warland, L.; Liu, Z. Optimal planning of the Nordic transmission system with $100 \%$ electric vehicle penetration of passenger cars by 2050. Energy 2016, 107, 648-660. [CrossRef]

20. Hui, L.; Yun, L.; Feng, L. Dynamic economic/emission dispatch including PEVs for peak shaving and valley filling. IEEE Trans. Ind. Electron 2018, 66, 2880-2890.

21. Mozafar, M.R.; Amini, M.H.; Moradi, M.H. Innovative appraisement of smart grid operation considering large-scale integration of electric vehicles enabling V2G and G2V systems. Electr. Power Syst. Res. 2018, 154, 245-256. [CrossRef]

22. Lance, N.; Regina, M.C. A cost benefit analysis of a V2G-capable electric school bus compared to a traditional diesel school bus. Appl. Energy 2014, 126, 246-255.

23. Zhao, Y.; Noori, M.; Tatari, O. Vehicle to Grid regulation services of electric delivery trucks: Economic and environmental benefit analysis. Appl. Energy 2016, 170, 161-175. [CrossRef]

24. Zhang, L.; Li, Y. Optimal Management for Parking-Lot Electric Vehicle Charging by Two-Stage Approximate Dynamic Programming. IEEE Trans. Smart Grid 2015, 8, 1722-1730. [CrossRef]

25. Lund, H.; Kempton, W. Integration of renewable energy into the transport and electricity sectors through V2G. Energy Policy 2008, 36, 3578-3587. [CrossRef]

26. Locment, F.; Sechilariu, M.; Forgez, C. Electric vehicle charging system with PV Grid-connected configuration. In Proceedings of the Vehicle Power \& Propulsion Conference, Chicago, IL, USA, 6-9 September 2012.

27. Göransson, L.; Karlsson, S.; Johnsson, F. Integration of plug-in hybrid electric vehicles in a regional wind-thermal power system. Energy Policy 2010, 38, 5482-5492. [CrossRef] 
28. Kou, P.; Liang, D.; Gao, L.; Gao, F. Stochastic Coordination of Plug-In Electric Vehicles and Wind Turbines in Microgrid: A Model Predictive Control Approach. IEEE Trans. Smart Grid 2016, 7, 1537-1551. [CrossRef]

29. Chukwu, U.C.; Mahajan, S.M. Real-Time Management of Power Systems with V2G Facility for Smart-Grid Applications. IEEE Trans. Sustain. Energy 2013, 5, 558-566. [CrossRef]

30. Alam, M.J.E.; Muttaqi, K.M.; Sutanto, D. Effective Utilization of Available PEV Battery Capacity for Mitigation of Solar PV Impact and Grid Support with Integrated V2G Functionality. IEEE Trans. Smart Grid 2015, 7, 1562-1571. [CrossRef]

31. Vachirasricirikul, S.; Ngamroo, I. Robust LFC in a Smart Grid with Wind Power Penetration by Coordinated V2G Control and Frequency Controller. IEEE Trans. Smart Grid 2014, 5, 371-380. [CrossRef]

32. Khodayar, M.E.; Wu, L.; Shahidehpour, M. Hourly Coordination of Electric Vehicle Operation and Volatile Wind Power Generation in SCUC. IEEE Trans. Smart Grid 2012, 3, 1271-1279. [CrossRef]

33. Fettinger, N.S.; Ten, C.W.; Chigan, C. Minimizing residential distribution system operating costs by intelligently scheduling plug-in hybrid electric vehicle charging. In Proceedings of the Transportation Electrification Conference and Expo (ITEC), Michigan, MI, USA, 18-20 June 2012.

34. Yang, H.; Chung, C.Y.; Zhao, J. Application of plug-in electric vehicles to frequency regulation based on distributed signal acquisition via limited communication. IEEE Trans. Power Syst. 2012, 28, 1017-1026. [CrossRef]

35. Sortomme, E.; El-Sharkawi, M.A. Optimal Scheduling of Vehicle-to-Grid Energy and Ancillary Services. IEEE Trans. Smart Grid 2011, 3, 351-359. [CrossRef]

36. Nezamoddini, N.; Wang, Y. Risk management and participation planning of electric vehicles in smart grids for demand response. Energy 2016, 116, 836-850. [CrossRef]

37. Sales ranking of EVs in 2019. Available online: https://www.sohu.com/a/371183113_205282 (accessed on 1 February 2020).

38. Gong, L.; Cao, W.; Zhao, J. Load modeling method for EV charging stations based on trip chain. In Proceedings of the 2017 IEEE Conference on Energy Internet and Energy System Integration, Beijing, China, 26-28 November 2017.

39. Weckx, S.; Driesen, J. Load Balancing With EV Chargers and PV Inverters in Unbalanced Distribution Grids. IEEE Trans. Sustain. Energy 2015, 6, 635-643. [CrossRef]

40. Wang, Y.; Huang, Y.; Wang, Y.; Yu, H.; Li, R.; Song, S. Energy Management for Smart Multi-Energy Complementary Micro-Grid in the Presence of Demand Response. Energies 2018, 11, 974. [CrossRef]

41. Badawy, M.O.; Sozer, Y. Power Flow Management of a Grid Tied PV-Battery System for Electric Vehicles Charging. IEEE Trans. Ind. Appl. 2017, 53, 1347-1357. [CrossRef]

42. Xie, D.; Chu, H.; Gu, C.; Li, F.; Zhang, Y. A Novel Dispatching Control Strategy for EVs Intelligent Integrated Stations. IEEE Trans. Smart Grid 2015, 21, 1. [CrossRef]

43. Dubey, A.; Santoso, S. Electric Vehicle Charging on Residential Distribution Systems: Impacts and Mitigations. IEEE Access 2015, 3, 1871-1893. [CrossRef]

44. Binetti, G.; Davoudi, A.; Naso, D.; Turchiano, B.; Lewis, F.L. Scalable Real-Time Electric Vehicles Charging With Discrete Charging Rates. IEEE Trans. Smart Grid 2015, 6, 2211-2220. [CrossRef]

45. Beaude, O.; Lasaulce, S.; Hennebel, M.; Mohand-Kaci, I. Reducing the Impact of EV Charging Operations on the Distribution Network. IEEE Trans. Smart Grid 2016, 7, 2666-2679. [CrossRef]

(C) 2020 by the authors. Licensee MDPI, Basel, Switzerland. This article is an open access article distributed under the terms and conditions of the Creative Commons Attribution (CC BY) license (http://creativecommons.org/licenses/by/4.0/). 